\title{
Ventral Medial Thalamic Nucleus Promotes Synchronization of Increased High Beta Oscillatory Activity in the Basal Ganglia-Thalamocortical Network of the Hemiparkinsonian Rat
}

\author{
Elena Brazhnik, ${ }^{\star}$ Alex J. McCoy, ${ }^{\star}$ Nikolay Novikov, Christina E. Hatch, and Judith R. Walters \\ Neurophysiological Pharmacology Section, National Institute of Neurological Disorders and Stroke, National Institutes of Health, Bethesda, Maryland \\ 20892-3702
}

Loss of dopamine is associated with increased synchronization and oscillatory activity in the subthalamic nucleus and basal ganglia (BG) output nuclei in both Parkinson's disease (PD) patients and animal models of PD. We have previously observed substantial increases in spectral power in the $25-40 \mathrm{~Hz}$ range in LFPs recorded in the substantia nigra pars reticulata (SNpr) and motor cortex (MCx) in the hemiparkinsonian rat during treadmill walking. The current study explores the hypothesis that SNpr output entrains activity in the ventral medial thalamus (VM) in this frequency range after loss of dopamine, which in turn contributes to entrainment of the MCx and BG. Electrode bundles were implanted in MCx, SNpr, and VM of rats with unilateral dopamine cell lesions. Spiking and LFP activity were recorded during epochs of rest and walking on a circular treadmill. After dopamine cell lesion, 30-36 Hz LFP activity in the VM became more robust during treadmill walking and more coherent with LFP activity in the same range in $\mathrm{MCx}$ and SNpr. Infusion of the GABA antagonist picrotoxin into the VM reduced both high beta power in MCX and SNpr and coherence between MCx and SNpr while temporarily restoring walking ability. Infusion of the $\mathrm{GABA}_{\mathrm{A}}$ agonist muscimol into the VM also reduced $\mathrm{MCx}-\mathrm{SNpr}$ coherence and beta power but failed to improve walking. These results support the view that synchronized neuronal activity in the VM contributes to the emergence of high beta oscillations throughout the BG-thalamocortical network in the behaving parkinsonian rat.

Key words: basal ganglia; beta oscillations; motor cortex; Parkinson's disease; substantia nigra; ventral medial thalamus

Significance Statement

Parkinson's disease symptoms are associated with dramatic increases in synchronized beta range (15-35 Hz) oscillatory local field activity in several brain areas involved in motor control, but the mechanisms promoting this activity and its functional significance remain unresolved. This oscillatory activity can be recorded in awake behaving rats with unilateral dopamine cell lesions using chronically implanted electrodes. Although these rats have motor deficits, they can walk on a circular treadmill in the direction ipsilateral to their lesion. This study establishes a critical role for the ventral medial thalamus in the propagation of this exaggerated beta range oscillatory activity and the sequential entrainment of structures throughout the basal ganglia-thalamocortical loop in the lesioned hemisphere of hemiparkinsonian rats during treadmill walking.

\section{Introduction}

Advanced-stage Parkinson's disease (PD) is associated with widespread dopamine loss in the basal ganglia (BG). This disorder is

\footnotetext{
Received Sept. 25, 2015; revised Feb. 8, 2016; accepted Feb. 19, 2016.

Author contributions: J.R.W. designed research; E.B., N.N., and C.E.H. performed research; A.J.M., N.N., and C.E.H. analyzed data; E.B., A.J.M., and J.R.W. wrote the paper.

This work was supported by the Intramural Research Program of the National Institutes of Health-National Institute of Neurological Disorders and Stroke. We thank Newlin Morgan, Tom Talbot, and Daryl Brandy in the National Institute of Mental Health Section on Instrumentation for design and fabrication of the rotary treadmill. The authors declare no competing financial interests.

*E.B. and A.J.M. contributed equally to this work and are co-first authors.
}

also associated with increases in oscillatory neuronal activity in the $12-30 \mathrm{~Hz}$ frequency range in the subthalamic nucleus (STN) and internal globus pallidus (Brown et al., 2001; Levy et al., 2002; Brown, 2003; Priori et al., 2004; Kühn et al., 2005; Weinberger et al., 2006). Although still a matter of debate, it has been hypothesized that this exaggerated oscillatory activity plays a direct role in

Correspondence should be addressed to Judith R. Walters, PhD, Neurophysiological Pharmacology Section, NINDS, NIH, 35 Convent Drive, Building 35 Room 1C905, Bethesda, MD 20892-3702. E-mail: waltersj@ninds.nih.gov. DOI:10.1523/JNEUROSCI.3582-15.2016

Copyright $\odot 2016$ the authors $\quad 0270-6474 / 16 / 364196-13 \$ 15.00 / 0$ 
the impairment of motor function in PD (Brown and Williams, 2005). Indeed, the ability of the dopamine precursor L-DOPA to reduce expression of this beta-range activity in the STN is significantly correlated with this treatment's ability to alleviate bradykinesia and rigidity in PD patients (Brown and Williams, 2005; Kühn et al., 2006; Weinberger et al., 2006).

Whatever role this exaggerated oscillatory activity plays in PD, it is clear that the emergence of this phenomenon represents a dramatic change in the dynamics of the BG network and its capacity to transmit information (Murer et al., 2002; Cruz et al., 2009; Wilson, 2013). A better understanding of how synchronized activity develops in this network after loss of dopamine and how it affects areas downstream from the BG would facilitate insight into the pathological significance of this activity with respect to motor function, as well as the processes regulated by BG output.

Rats with unilateral dopamine cell lesions (hemiparkinsonian rats) exhibit motor deficits resembling those observed in PD patients. These include impaired function of the contralateral limb and difficulties with gait that are reversed by L-DOPA treatment (Cenci et al., 2002). By 1 week after dopamine cell lesion, these rats also show increased oscillatory LFP activity in the high beta $25-40 \mathrm{~Hz}$ range in the substantia nigra pars reticulata (SNpr) and STN of the lesioned hemisphere during treadmill walking, which is coherent with increased activity in the same range in the ipsilateral motor cortex (MCx) (Avila et al., 2010; Brazhnik et al., 2012; Brazhnik et al., 2014; Delaville et al., 2014; Delaville et al., 2015). These increases in high beta LFP activity are also reduced after L-DOPA administration and show amplitude modulation in conjunction with motor activity (Avila et al., 2010; Brazhnik et al., 2012; Brazhnik et al., 2014; Delaville et al., 2015). Therefore, although the frequency range of the exaggerated beta activity observed in the hemiparkinsonian rats is higher than that observed in PD patients (Brown, 2003; Gatev et al., 2006; Weinberger et al., 2006), similarities between these phenomena suggest that the rodent model may provide insight into mechanisms supporting the emergence of this activity. Indeed, observations of coherent synchronized activity in the MCx, STN, and SNpr suggest that this activity may subsequently induce oscillatory activity in the principle target of BG output, the ventral medial thalamus (VM) (Herkenham, 1979; Kuramoto et al., 2011; Kuramoto et al., 2015). These observations raise the possibility that activity throughout the BG-thalamocortical loop becomes similarly entrained, with loss of dopamine promoting a new dynamic state in this network with a resonance frequency in the rat in the high beta range.

The goal of the present study was to explore this possibility through a series of chronic recordings in the BG-thalamocortical circuit in control and lesioned hemispheres of awake, behaving hemiparkinsonian rats. Paired recordings from the $\mathrm{MCx}-\mathrm{SNpr}$, $\mathrm{SNpr}-\mathrm{VM}$, and $\mathrm{MCx}-\mathrm{VM}$ during epochs of inattentive rest and circular treadmill walking were examined to investigate the hypothesis that the VM thalamus contributes to the transmission of the exaggerated high beta oscillatory activity observed in the BG and MCx in these animals in the dopamine cell-lesioned hemisphere. In addition, GABAergic agents were injected into the VM while recordings were obtained from the MCx and SNpr to determine whether alterations in thalamic activity would affect high beta synchronization in other nodes of the BG-thalamocortical circuit and alter motor function.

\section{Materials and Methods}

Procedures. All experimental procedures were conducted in accordance with the National Institutes of Health's (NIH's) Guide for Care and Use of Laboratory Animals and were approved by the National Institute of Neu- rological Disorders and Stroke (NINDS) Animal Care and Use Committee. Every effort was made to minimize the number of animals used and their discomfort.

Subjects and behavioral training. Male Long-Evans rats (Taconic Farm) weighing 250-300 g were housed with ad libitum access to chow and water in environmentally controlled conditions with a reversed 12/12 h light/dark cycle (lights on at 18:00 h). A week before the surgery, rats were handled daily and trained to walk on a circular rotating treadmill custom built by the NIMH Section on Instrumentation, NIH (Avila et al., 2010). Training consisted of 3-5 daily sessions during which rats were encouraged to walk for 5-10 $\mathrm{min}$ in both clockwise and counterclockwise directions with rest periods between walking epochs. At the end of the training, rats were able to walk steadily in both directions at the speed of 9 RPM. After unilateral dopamine cell lesion, the hemiparkinsonian rats could walk reasonably well on the circular treadmill if they were oriented in the direction ipsiversive to the dopamine cell-lesioned hemisphere with their affected paws on the outside of the circular path, but they had significant difficulty walking in the direction contraversive to the lesion with their affected paws on the inside of the circular track. Overall, 35 rats were included to the study; of these, 27 received unilateral neurotoxin 6-hydroxydopamine (6-OHDA) lesion.

Surgical procedures. Unilateral lesion of the nigrostriatal pathway and implantation of electrodes for recording LFP and spikes were performed during the same surgery. Rats were anesthetized with $75 \mathrm{mg} / \mathrm{kg}$ ketamine and $0.5 \mathrm{mg} / \mathrm{kg}$ medetomidine intraperitoneally and placed in a stereotaxic frame (David Kopf Instruments) with heads fixed with atraumatic ear bars. The incision area was shaved and a long-acting local anesthetic ( $1 \%$ mepivacaine $\mathrm{HCl}$ solution) was injected along the intended incision lines. Ophthalmic ointment was applied to prevent corneal dehydration and lidocaine gel was placed in the ear canals. A heating pad was used to maintain body temperature at $37^{\circ} \mathrm{C}$. Small supplemental doses of ketamine were administered during the surgery as needed.

Unilateral lesion of the nigrostriatal pathway. Before intracerebral injection of 6-OHDA (Sigma-Aldrich) into the left medial forebrain bundle to destroy the dopaminergic nigrostriatal pathway, desmethylimipramine $\mathrm{HCl}(30 \mathrm{mg} / \mathrm{kg}$, i.p. $)$ was administered to protect noradrenergic neurons. A hole was drilled in the skull at $4.4 \mathrm{~mm}$ anterior to the lambdoid suture and $1.2 \mathrm{~mm}$ lateral to sagittal suture. Six micrograms of 6-OHDA $\mathrm{HBr}$ in $3 \mu \mathrm{l}$ of $0.9 \%$ saline with $0.01 \%$ ascorbic acid were infused via a 27 gauge stainless steel cannula into the medial forebrain bundle ( $8.3 \mathrm{~mm}$ ventral to the skull surface) at a rate of $1 \mu \mathrm{l} / \mathrm{min}$ over 3 min via a syringe pump (Harvard Apparatus). The cannula was left at the target site for $3 \mathrm{~min}$ after the infusion was completed. The efficacy of the dopamine cell lesion was assessed using the stepping test procedure at 5-7 d after the lesion (Olsson et al., 1995; Schallert and Tillerson, 1999). Rats were included in the study if they demonstrated a strong unilateral motor deficit (number of steps made by the contralateral limb $<5 \%$ of steps made by the ipsilateral limbs) after the dopamine cell lesion. The extent of dopamine cell degeneration was verified postmortem using immunohistochemistry for tyrosine hydroxylase staining (see below).

Electrode placement. Twelve rats were implanted with electrode bundles (NB Laboratories) bilaterally in the VM thalamic nucleus and the MCx. Ten of these rats received unilateral 6-OHDA lesion and one did not receive MCx electrodes. A second group of rats $(n=13)$ was unilaterally implanted with the electrodes in the MCx, SNpr, and VM, 9 of which received 6-OHDA lesion in the same hemisphere. A third group of rats $(n=10)$ was unilaterally implanted with electrodes in the SNpr and $\mathrm{MCx}$ and a cannula in the VM for the administration of drugs, 8 of which received 6-OHDA lesion. The 10 bilaterally implanted and lesioned rats constituted the data in Figure 1 which shows LFP power in simultaneous bilateral recordings. The bilateral VM, unilateral MCx-SNpr-VM, and $\mathrm{MCx}-\mathrm{SNpr}-\mathrm{VM}$ cannula groups were combined for $\mathrm{MCx}-\mathrm{VM}$ and SNpr-VM coherence and for interregional spike-LFP relationships (see Figs. 2, 3); MCx, 22 lesion and 21 control recordings, 9 of them paired; SNpr, 13 lesion and 8 control; VM, 16 lesion and 17 control, 10 of them paired.

During surgery, holes were drilled in the skull for electrode placement in the VM (posterior $2.5 \mathrm{~mm}$ from the bregma, lateral $\pm 1.5 \mathrm{~mm}$ from the 
sagittal suture and ventral 7.1-7.2 $\mathrm{mm}$ from the skull surface), $\mathrm{SNpr}$ (anterior $3.2 \mathrm{~mm}$ from the lambdoid suture, lateral $\pm 2.2 \mathrm{~mm}$ from the sagittal suture and ventral $8.0 \mathrm{~mm}$ from the skull surface) and $\mathrm{MCx}$ (anterior $2.0 \mathrm{~mm}$ from the bregma, lateral $\pm 2.5 \mathrm{~mm}$ from the sagittal suture, and ventral $2.0 \mathrm{~mm}$ from the skull surface). Electrode bundles were implanted in the target regions and secured to the skull with screws and dental cement. Each bundle consisted of 8 stainless steel Tefloninsulated microwires plus an additional ninth wire with no insulation for $\sim 1 \mathrm{~mm}$ on the recording tip serving as a local reference. Ground wires from each set of electrodes were wrapped around a screw located above the cerebellum. Instead of having an electrode bundle implanted in the $\mathrm{VM}$, one group of rats was implanted with a guide cannula (26-gauge; Plastics One) above the VM in the lesioned hemisphere for infusion of drugs and vehicle (saline). Stylets were inserted into the cannula. After completion of surgical procedures, atipamezole $(0.3-0.5 \mathrm{mg} / \mathrm{kg}$, s.c. $)$ was administered to reverse the anesthetic effects of medetomidine and ketamine and ketofluid was given subcutaneously. Recordings began after recovery of the animals, 1 week after surgery. Rats were retrained on the rotating treadmill walking task before the recordings session started.

Electrophysiological recordings. Extracellular unit and LFP recordings were performed starting on day 7 after surgery. Data were collected during epochs of inattentive rest and walking on the rotating circular treadmill at a standard rotation speed of 9 RPM. Data for comparisons of the effect of the L-DOPA treatment on the LFP activity in the lesioned and nonlesioned hemisphere recordings were obtained before and after drug administration at days 21-42 after lesion while rats were walking in the direction ipsiversive to the lesioned hemisphere. To assess motor deficits and the effects of drug treatment on gait, data were also collected when rats were walking in the direction contraversive to the lesioned hemisphere.

Extracellular spike trains and LFPs were amplified and filtered using Plexon preamplifiers and sampled with the Micro1401 data acquisition interface (Cambridge Electronic Design). Spikes and LFPs from signal wires were referenced to the ninth wire in the same bundle. Sampling rates were $40 \mathrm{kHz}$ for spike trains and 1 or $2 \mathrm{kHz}$ for LFPs. Action potentials were amplified $(10,000 \times)$ and bandpass filtered $(0.15-9 \mathrm{kHz})$. LFPs were amplified $(1000 \times)$ and bandpass filtered $(0.07-500$ or 1000 $\mathrm{Hz}$ ). Discriminated spike signals and LFPs recordings were digitized, stored and analyzed offline using Spike2 software.

Drug administration. Drugs (Sigma-Aldrich) were dissolved in sterile saline. L-DOPA was administrated at a therapeutic dose of $5 \mathrm{mg} / \mathrm{kg}$, supplemented with $15 \mathrm{mg} / \mathrm{kg}$ benserazide hydrochloride intraperitoneally. The D2 dopamine receptor antagonist eticlopride was injected at a dose of $0.2 \mathrm{mg} / \mathrm{kg}$ subcutaneously. Muscimol, a GABA $\mathrm{A}_{\mathrm{A}}$ long-acting agonist ( $40 \mathrm{ng}$ in $0.5 \mu \mathrm{l}$ ); picrotoxin, a GABA $\mathrm{A}_{\mathrm{A}}$ receptor antagonist (50 ng in $0.5 \mu \mathrm{l})$; and sterile saline $(0.5 \mu \mathrm{l}, 0.9 \%$, UPS $)$ were infused into the VM via a microinjection needle (33-gauge; Plastics One) extended $1.0 \mathrm{~mm}$ beyond the tip of the guide cannula. A $10 \mu$ l Hamilton syringe was attached to the injection needle by polyethylene tube (PE-50; Plastics One). All infusions were made at a rate of $1 \mu \mathrm{l} / \mathrm{min}$ using an infusion pump (Harvard Apparatus). The injection needle was left for an additional 2-3 min after each injection to allow for adequate diffusion.

Data analysis. Periods of LFP and spike recordings free of major artifacts were taken for analysis. Direct observation and videotaped motor behavior were used for selection of epochs representing different behavioral states. For spike-triggered waveform averages (STWAs) and LFP power, epochs of $100 \mathrm{~s}$ were taken during walking on the circular treadmill in the direction ipsiversive to the lesioned hemisphere unless otherwise indicated. Epochs of inattentive rest were also analyzed, although the length of inattentive rest epochs was variable.

Spectral analysis of LFP recordings. Before power and coherence analysis, LFP recordings were smoothed to $500 \mathrm{~Hz}$. For each rat, two inattentive rest epochs and two treadmill walking epochs with consistent behavior were considered. LFP power was calculated by fast Fourier transform (FFT) with a frequency resolution of $\sim 1 \mathrm{~Hz}$. Total spectral power was calculated using a Spike2 script and exported to Microsoft Excel. A custom Excel script was used to integrate and measure total power in several frequency ranges: $12-18 \mathrm{~Hz}$ (low beta), $18-25 \mathrm{~Hz}$ (beta), $30-36 \mathrm{~Hz}$ (high beta), and $40-50 \mathrm{~Hz}$ (low gamma). The resulting total power was then normalized by total power within the $200-250 \mathrm{~Hz}$ range.
Spectral coherence was calculated for LFP from each pair of electrodes ( $\mathrm{MCx}-\mathrm{VM}, \mathrm{MCx}-\mathrm{SNpr}$, and SNpr-VM) with a Spike2 script using FFTbased spectral coherence.

To identify significant peaks in LFP power and coherence spectra, the following criteria were used: (1) a relative maximum in the spectrum must be greater than the surrounding $161 \mathrm{~Hz}$ bins; (2) the slope of the curve changed from positive to negative after the maximum derivative of the spectrum; and (3) the second derivative at the relative maximum must be negative, indicating a downward concavity (Brazhnik et al., 2012).

To visualize spectral power changes over time for the selected epochs, time-frequency wavelet spectra were constructed using continuous wavelet transforms. The Morlet wavelet was applied to the LFPs using 128 frequency scales and a time resolution of $\sim 750 \mathrm{~ms}$ (Time-frequency Toolbox; http://tftb.nongnu.org). Time-frequency coherence for each pair of electrodes (MCx-VM, MCX-SNpr, and SNpr-VM) was calculated using fast FFT-based coherence over a 10 second sliding window (http://chronux.org).

The multitaper coherence analysis applied using Chronux introduced a bias determined by the following formula: $B=\frac{1}{\sqrt{v}}$, where $B$ is the bias introduced by the analysis and $\nu$ is the degrees of freedom (Mitra and Bokil, 2008). This multitaper calculation used 19 tapers, providing 19 degrees of freedom, resulting in a bias of $\sim 0.23$. To compensate for this, the smallest coherence values in the plot were assigned to 0.23 and the largest to 1.23 rather than 0 and 1 , respectively.

Cell sorting and spike-triggered waveform analysis. Spike waveforms were sorted using principal components analysis in Spike2. To assess effective sorting for single cells, interspike interval histograms were generated and inspected to ensure that that spikes were not occurring within the assumed refractory period of $1 \mathrm{~ms}$. To evaluate the temporal relationship between the spiking activity of individual neurons and LFPs, STWAs were calculated during inattentive rest and treadmill walking epochs. LFPs were band-pass filtered to the desired frequency range. STWAs were generated from epochs of single-unit spike train and LFP recordings from the lesioned and nonlesioned hemispheres. Various measurements were taken of each STWA, including the peak-to-trough amplitude, the period of the averaged waveform oscillation around the spike, and the phase of the spike with respect to the maximum positive deflection of the surrounding averaged waveform oscillation. Subsequently, for each spike train, a further set of 20 STWAs were generated from 20 different randomly shuffled versions of the original spike train. The resulting 20 STWA peak-to-trough amplitudes were averaged for comparison with the unshuffled waveform average. Spikes were considered to be significantly correlated with the LFP oscillations when the peak-to-trough amplitude of the unshuffled spike train STWA was greater than the mean of the 20 peak-to-trough amplitudes of the shuffled spike trains plus three SDs of this mean. Phase calculations were only considered for significantly correlated spike trains. Epochs during which spike trains exhibited a firing rate of $<2.0 \mathrm{~Hz}$ were not considered.

Motor performance. Motor activity was monitored online and videotaped for offline review. To quantify the motor performance of the intact and dopamine-depleted rats during walking in a circular treadmill, the steps made by each of the back paws (i.e., the paws toward the inside and the outside of the circular treadmill track) were counted during two consecutive $30 \mathrm{~s}$ epochs of walking in each direction. The ratio of steps made by the inside paw relative to steps made by the outside paw was calculated (in/out ratio) (Brazhnik et al., 2012; Brazhnik et al., 2014).

Histology and immunochemistry. After recordings were completed, rats were deeply anesthetized with urethane $(1.6 \mathrm{~g} / \mathrm{kg}$, i.p.) and recording sites were marked by passing a $10 \mu \mathrm{A}$ positive current for $10 \mathrm{~s}$ through $2-3$ microwires. Rats were perfused intracardially with $200 \mathrm{ml}$ of cold saline, followed by $200 \mathrm{ml}$ 4\% paraformaldehyde in PBS. Brains were postfixed in paraformaldehyde solution overnight and then immersed in $10 \%$ sucrose in PBS (0.1 M, pH 7.4). Coronal sections of $40 \mu \mathrm{m}$ for electrode placement verification were mounted on glass slides and stained with cresyl violet and $5 \%$ potassium ferricyanide $/ 9 \% \mathrm{HCl}$ to reveal the iron deposited at the electrode tips.

To assess loss of dopaminergic neurons in the substantia nigra, a standard immunohistochemical protocol was used for staining tyrosine hy- 
droxylase (TH) in freely floating sections (Avila et al., 2010; Brazhnik et al., 2012; Brazhnik et al., 2014). The extent of dopamine cell degeneration was assessed by examination and digitization of the image under the light microscope obtained with wide-field optics, allowing simultaneous capture of both lesioned and nonlesioned hemispheres. The optical density values of TH fibers and neurons in the SNpc were measured (using ImageJ software) in anterior, middle, and posterior sections of the substantia nigra in the lesioned hemisphere and compared with density in homologous regions in the nonlesioned hemisphere. TH density in the substantia nigra from the lesioned hemisphere was $<90 \%$ of that in the nonlesioned hemisphere.

Statistical analysis. Total LFP power, pairwise coherence, and STWA ratios in lesioned and nonlesioned hemispheres, time dependent effects of drug administration on the LFP total power, and motor behavior were compared using repeated-measures one- or two-way ANOVA with frequency or time as the repeated measure. Student-Newman-Keuls post hoc test was applied to acquire significant differences between the groups. In cases in which the data did not meet the assumptions of normal distribution and/or equal variance, Kruskal-Wallis one-way ANOVA with Dunn's post hoc comparison was used. The difference between the two groups of variables was assessed by $t$ test or the Mann-Whitney test. The difference in proportion of significantly correlated neurons between the lesioned and nonlesioned hemispheres was evaluated with a $\chi^{2}$ test. To show that spiking is significantly phase oriented to LFPs, the Rayleigh test was applied to polar data. Significant difference in a distribution of spike-LFP phases between the three recording regions was evaluated using the Mardia-Watson-Wheeler test. Unless stated otherwise, all results in this manuscript are presented as the mean value \pm SEM. Polar data are reported as mean angle \pm standard angular deviation. Statistical analysis was performed with SigmaPlot (SyStat Software). The minimum criterion of significance was $\alpha=0.05$.

\section{Results}

\section{Oscillatory LFP activity in VM thalamus after dopamine} cell lesion

Chronic recordings from electrodes implanted bilaterally in the VM demonstrate that high beta $(30-36 \mathrm{~Hz})$ LFP power is significantly increased in the VM in the lesioned hemisphere during treadmill walking relative to the nonlesioned hemisphere (Fig. 1). Notably, this increase is similar to that observed in previous recordings from the SNpr, STN, and layer 5/6 of the MCx after dopamine cell lesion during treadmill walking (Avila et al., 2010; Brazhnik et al., 2012; Brazhnik et al., 2014; Delaville et al., 2015). Here, LFP recordings were obtained from bilateral chronically implanted electrodes in the VM of the hemiparkinsonian rat during inattentive rest and ipsiversive treadmill walking, starting at day 7 after lesion $(n=10)$. Representative wavelet-based scalograms (Fig. $1 A$ ) show a distinct band of LFP activity in the high beta $30-36 \mathrm{~Hz}$ range in the lesioned hemisphere of the VM thalamus during treadmill walking at day 28 after lesion. This activity is also reflected in the mean power spectra (Fig. 1E) from LFP recordings at day 21-28 and is absent in the nonlesioned hemisphere (Fig. $1 B, E$ ). Total 30-36 Hz LFP normalized power in the VM of the lesioned hemisphere was significantly increased during treadmill walking relative to the nonlesioned hemisphere at the time of the first recordings at day 7 after lesion $(2.62 \pm 0.4 \mathrm{vs}$ $1.23 \pm 0.2, p<0.05$, data not shown) and further increased at day $21-28$ (3.50 $\pm 0.5, p<0.05$; Fig. $1 G)$. The mean peak frequency of high beta activity in the VM at day $21-28$ was $32.5 \pm 0.8 \mathrm{~Hz}$. Total VM LFP power in the other frequency ranges examined, the $12-18,18-25$, and $40-50 \mathrm{~Hz}$ gamma ranges, was not significantly different between the lesioned and nonlesioned hemispheres during treadmill walking $(p>0.05)$.

In contrast to differences observed between lesioned and nonlesioned hemispheres in the high beta range during treadmill walking, no significant differences in this range were observed between the two hemispheres during inattentive rest at day 7 (data not shown) and days 21-28 after lesion; that is, no significant beta range peaks were observed in either hemisphere in power spectra derived from rest epochs (Fig. $1 E$, insert), nor in VM mean normalized total LFP power over a series of discrete frequency ranges from 12 to $50 \mathrm{~Hz}$ (Fig. $1 F$ ).

\section{Effect of treatment with L-DOPA on $30-36 \mathrm{~Hz} \mathrm{VM}$ thalamus LFP activity}

To show that the exaggerated high beta LFP activity in the VM evident during treadmill walking is associated with a loss of dopamine receptor stimulation, rats were treated with a therapeutic dose of L-DOPA ( $5 \mathrm{mg} / \mathrm{kg}$ with $15 \mathrm{mg} / \mathrm{kg}$ benserazide, i.p.). L-DOPA treatment significantly reduced VM $30-36 \mathrm{~Hz}$ power in the lesioned hemisphere during treadmill walking ipsiversive to the lesion ( $3.5 \pm 0.5$ vs $1.5 \pm 0.3, p<0.05, n=8)$, as shown by the representative wavelet scalogram in Figure $1 C$. The L-DOPAinduced reduction in high beta power in the VM was correlated with improvement in treadmill walking in the direction contraversive to the lesioned hemisphere. There was no significant difference in step count ratios for the inner to outer hind limbs during ipsiversive and contraversive walking after L-DOPA treatment (paired $t$ test, $p>0.05)$ compared with before L-DOPA $(p<0.001, n=6)$ (data not shown). The reduction in $30-36 \mathrm{~Hz}$ VM LFP normalized power induced by L-DOPA treatment was reversed by subsequent administration of the D2 dopamine receptor antagonist eticlopride $(1.0 \pm 0.3$ after L-DOPA vs $2.3 \pm$ 0.5 after eticlopride, $p<0.05, n=4)$, in conjunction with reversal of L-DOPA-induced improvement in contraversive walking on the circular treadmill (data not shown). The results are consistent with our previous studies in SNpr, STN, and MCx (Avila et al., 2010; Brazhnik et al., 2012; Brazhnik et al., 2014; Delaville et al., 2015) and support the idea that loss of dopamine receptor stimulation leads to excessive high beta range synchronization in the BG-thalamocortical loop, as well as motor deficits in treadmill walking.

\section{Relationship between VM thalamus spiking activity and LFPs}

Spike-LFP relationships were examined in the VM to determine whether changes in spike timing correlate with the increases in LFP beta range activity observed after dopamine cell lesion. The mean ratios of unshuffled-to-shuffled STWA peak-to-trough amplitudes of the VM neurons referenced to VM LFPs were compared between the lesioned and nonlesioned hemispheres (see Materials and Methods). Figure $1 H$ depicts typical unshuffled and shuffled STWAs from the lesioned VM during treadmill walking.

Notably, increases in VM power in the $30-36 \mathrm{~Hz}$ range in the lesioned hemisphere during treadmill walking were clearly associated with increased synchronization of spikes to LFP oscillations in the same frequency range. This was evident when we looked at spike-LFP relationships at the population level. First, the mean of the unshuffled-to-shuffled peak-to-trough STWA amplitude ratios for all epochs of VM spiking examined in the lesioned hemispheres was significantly greater than the mean of all ratios from the control hemispheres $(p<0.001$; Fig. $1 J)$. Second, the proportion of spike trains correlated to VM LFP was significantly higher in the lesioned hemisphere $(76 \%, n=72$ STWAs from 36 spike trains $(p<0.001$; Fig. $1 I)$ compared with the control hemisphere $(50 \%, n=88$ STWAs from 44 spike trains, 10 rats). These data are consistent with previous observations (Avila et al., 2010; Brazhnik et al., 2012; Brazhnik et al., 2014; Delaville et al., 2015) of significant spike locking to in- 


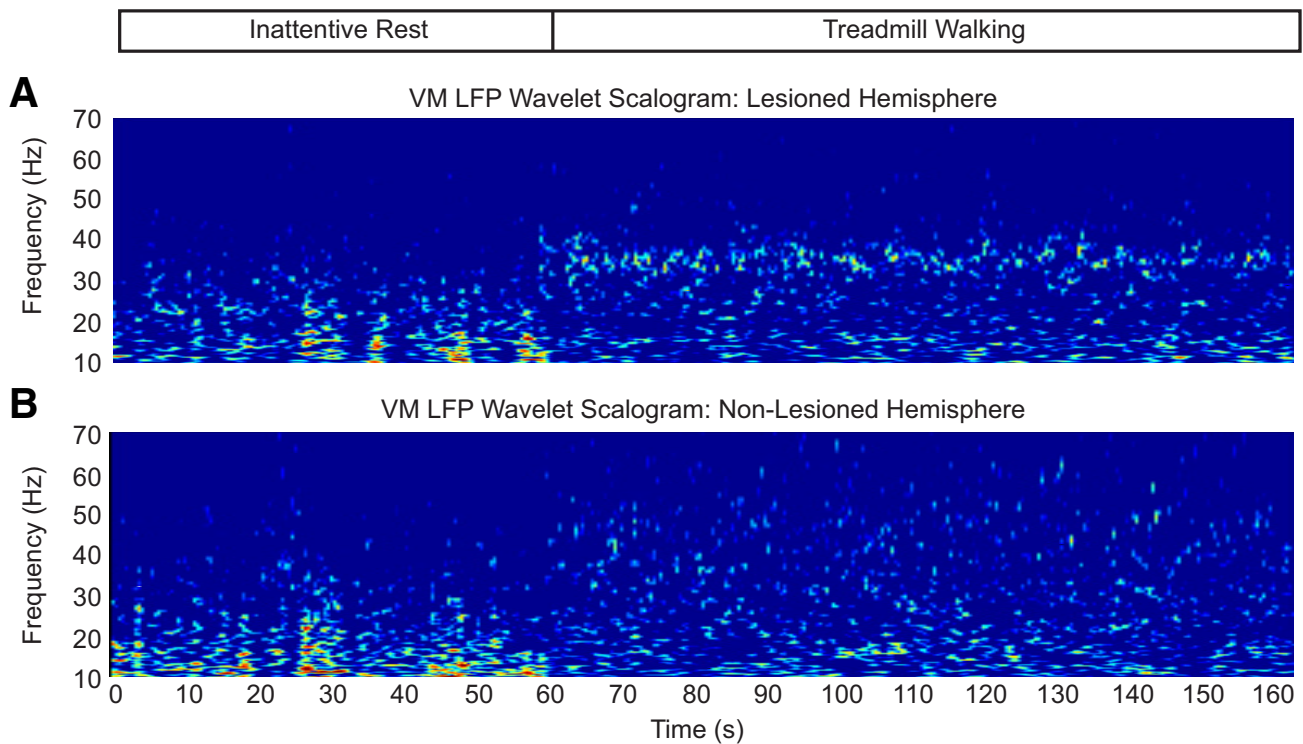

E

VM LFP Power Spectra: Walk

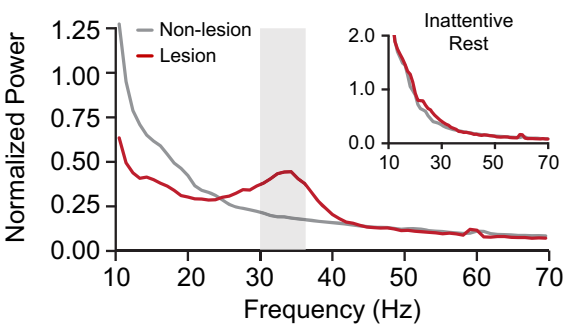

F VM LFP Power: Inattentive Rest
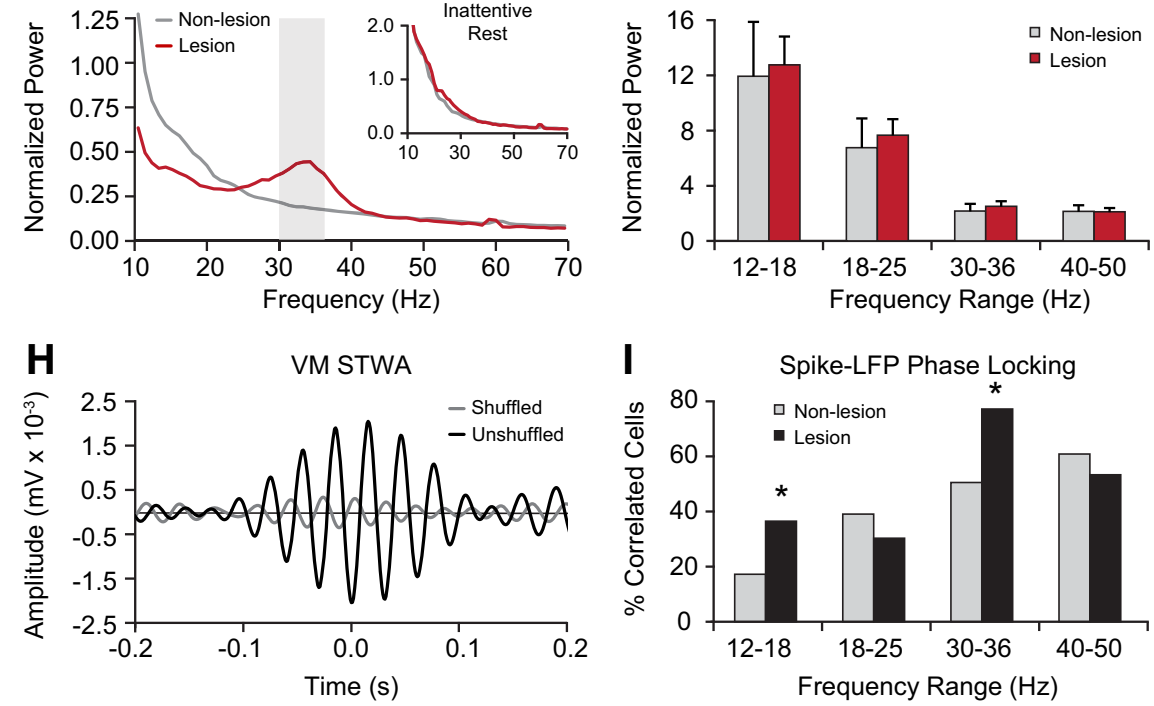

G
Treadmill Walking

C

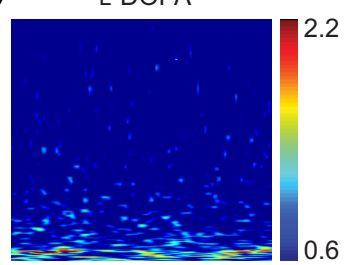

D

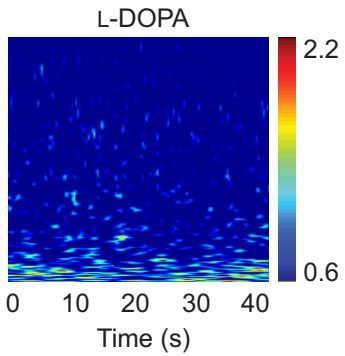

VM LFP Power: Walk
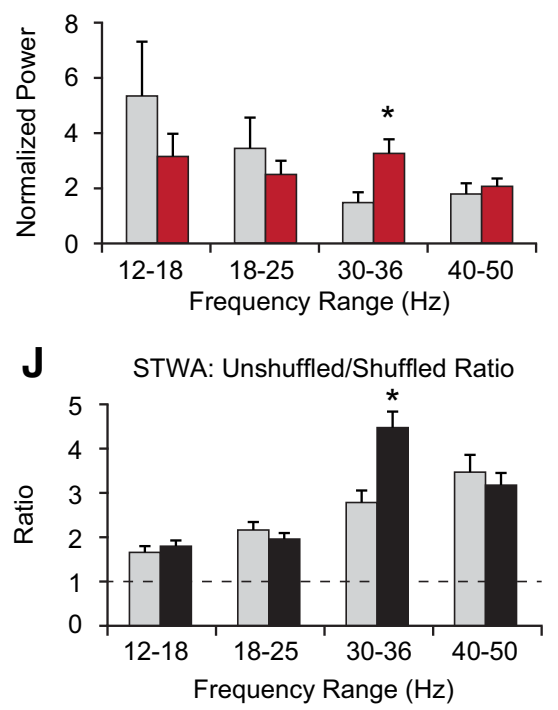

Figure 1. LFP power in paired recordings from the VM in nonlesioned and dopamine cell-lesioned hemispheres during periods of rest and treadmill walking. Recordings are from days $21-28$ after lesion ( $n=10$ rats). $\boldsymbol{A}, \boldsymbol{B}$, Representative time-frequency wavelet scalograms of LFP spectral power in recordings from VM during rest and walking (horizontal bar above). Power is plotted on a logarithmic scale with greater values represented by red. Note the emergence of the high beta oscillatory band in the VM scalogram from the lesioned hemisphere during walking. $\boldsymbol{C}, \boldsymbol{D}$, Reduction of the high beta/low gamma Hz LFP oscillations in the VM spectral power scalogram in the lesioned hemisphere after treatment with L-DOPA in recordings from the same animal as in $\boldsymbol{A}$ and $\boldsymbol{B}$. $\boldsymbol{E}$, Averaged power spectra of VM LFP from the lesioned (red) and nonlesioned (gray) hemispheres during treadmill walking and rest (inset). $F, G$, Averaged total LFP power (mean \pm SEM) within discrete frequency ranges shows significantly increased values in the $30-36 \mathrm{~Hz}$ range in the lesioned hemisphere during walking $(\boldsymbol{G})$ relative to rest $(\boldsymbol{F})$ and the nonlesioned hemisphere $(p<0.05)$. $\boldsymbol{H}$, Example of VM spike-LFP synchronization in the $30-36 \mathrm{~Hz}$ range from the lesioned hemisphere during walking. Graph shows the STWAs from the original spike train (black) and the shuffled spike train (gray). $I, J$, Proportion of VM STWAs showing significant phase locking of spike trains with LFP activity $(I)$ and mean STWA-based amplitude ratios $(J)$ are significantly higher in the $30-36 \mathrm{~Hz}$ range in the lesioned hemisphere (black bars) relative to the nonlesioned hemisphere (gray bars) $(p<0.001)$. Dashed line in $J$ indicates ratio $1 .{ }^{*}$ Significant difference between lesioned and nonlesioned hemispheres.

creased beta range LFP oscillations in the STN and SNpr of the dopamine cell-lesioned hemisphere and supports expectations that synchronous high beta inhibitory input from the SNpr to the VM would lead to entrainment of oscillatory spiking activity in the VM in the same frequency range.

High beta coherence between LFPs from VM, SNpr, and MCx during treadmill walking

To gain further insight into the role of the VM thalamus in mechanisms underlying the emergence of $30-36 \mathrm{~Hz}$ oscillatory LFP activity in the $\mathrm{BG}$ and $\mathrm{MCx}$ after dopamine cell lesion, mean LFP power in this range in VM was compared with LFP power in $\mathrm{MCx}$ and SNpr. Coherence between MCx-VM and SNpr-VM LFPs was also examined, together with $\mathrm{MCx}-\mathrm{SNpr}$ coherence during epochs of treadmill walking.

Previously, we have shown increases in LFP total power in MCX and SNpr LFPs and MCX-SNpr coherence in the 25-40 Hz range in the hemiparkinsonian rat during treadmill walking (Brazhnik et al., 2012). The current results (Fig. 2) show similar increases in VM LFP power and VM LFP coherence, with both $\mathrm{MCx}$ and SNpr LFPs in the $30-36 \mathrm{~Hz}$ range in the dopamine celllesioned hemisphere relative to controls during treadmill walking. The mean LFP power in the $30-36 \mathrm{~Hz}$ range was significantly greater in the lesioned hemisphere relative to control in all three 
A

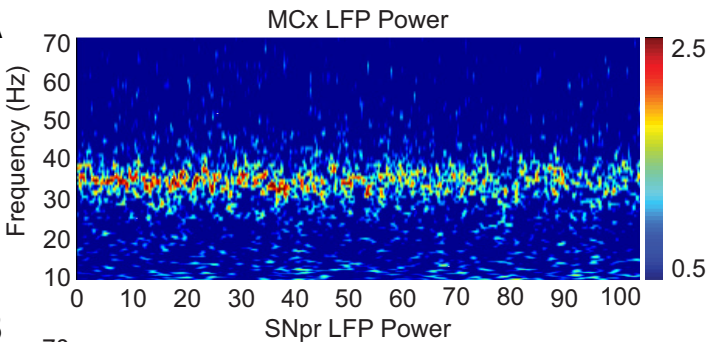

B

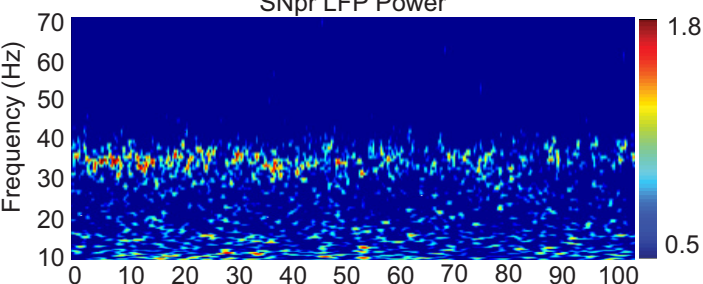

C

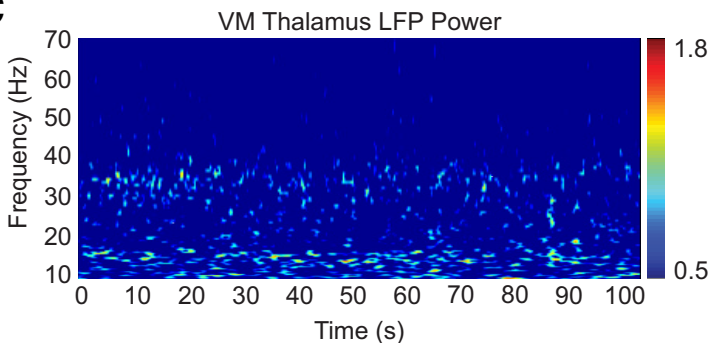

D

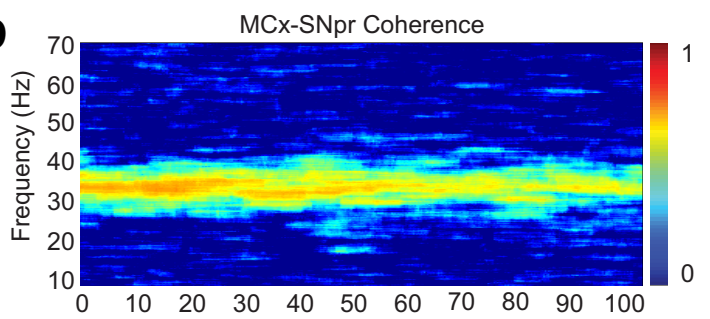

E
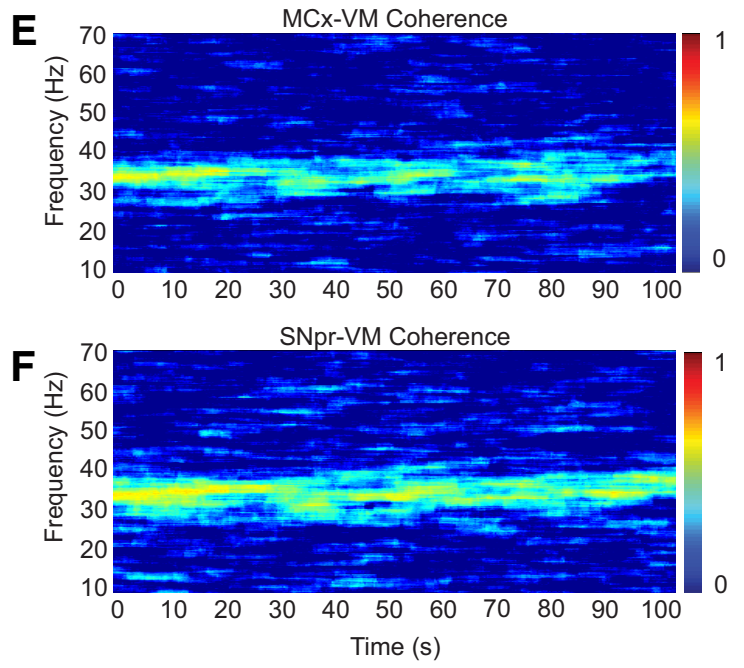
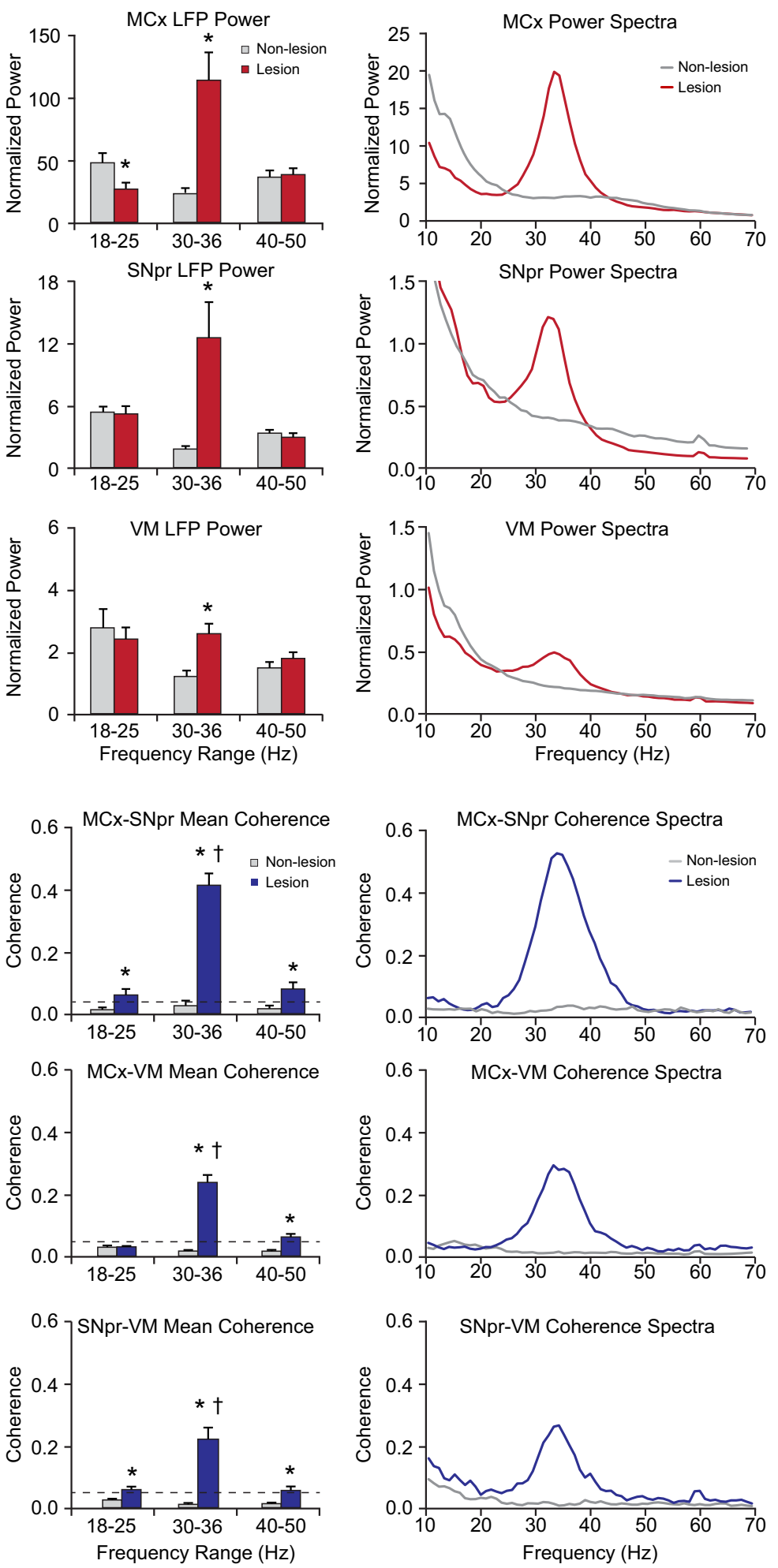

Figure 2. LFP oscillatory activity in the MCX, SNpr, and VM thalamus in dopamine cell-lesioned and nonlesioned hemispheres during treadmill walking. $\boldsymbol{A}-\boldsymbol{C}$, LFP power. Left, Representative time-frequency wavelet-based scalograms of LFP spectral power in the lesioned hemisphere plotted on a logarithmic scale. Middle, Averaged normalized LFP total power (mean \pm SEM) over a range of frequencies during treadmill walking. Right, Averaged and normalized LFP power spectra. $\boldsymbol{D}-\boldsymbol{F}$, Coherence of LFP activity within BG-thalamocortical circuit. Left, FFT-based time-frequency coherence between $M C x$ and $S N p r(\boldsymbol{D}), M C x$ and VM $(\boldsymbol{E})$, and SNpr and VM $(\boldsymbol{F})$ in the lesioned hemisphere. Coherence spectrograms are plotted on a linear scale with greater values represented by red. Middle, Averaged coherence (mean \pm SEM) in low beta $(18-25 \mathrm{~Hz})$, high beta $(30-36 \mathrm{~Hz})$, and gamma $(40-50 \mathrm{~Hz})$ frequency ranges. Right, Averaged coherence spectra. Note the emergence of synchronized oscillations in the high beta-frequency range in recording from all three regions in the dopamine cell-lesioned hemisphere. Evident in bars and spectra $(\boldsymbol{A}-\boldsymbol{F}$, middle and right) are significant increases in the $\mathrm{MCX}$, SNpr, and VM power $(p<0.05)$ and coherence $(p<0.01)$ between these nodes of the $B G$-thalamocortical circuit within the $30-36 \mathrm{~Hz}$ frequency range in the lesioned hemispheres. ${ }^{*}$ Significant difference between lesioned and nonlesioned hemispheres. tSignificant difference in coherence between frequency ranges. 
regions during treadmill walking: $\mathrm{MCx}(p<0.001, n=21$ and 22; Fig. $2 A)$, SNpr $(p<0.05, n=13$ and 8 ; Fig. $2 B)$, and VM $(p<$ $0.001, n=17$ and 18 rats, lesion and nonlesion respectively; Fig. $2 C)$. The increases in high beta (30-36) Hz VM LFP power were consistently associated with increased coherence in the same frequency range between VM and $\mathrm{MCx}$ (Fig. 2E) and between VM and SNpr (Fig. $2 F$ ). During treadmill walking, $\mathrm{MCx}-\mathrm{VM}$ and SNpr-VM coherence was significantly and robustly increased in the $30-36 \mathrm{~Hz}$ range in the lesioned hemisphere relative to control (MCx-VM, $p<0.001, n=16$ and 17; SNpr-VM, $p<0.01, n=$ 7 and 4$)$ and significantly greater than $\mathrm{MCx}-\mathrm{VM}$ and SNpr-VM LFP coherence in the $18-25$ and $40-50 \mathrm{~Hz}$ frequency ranges $(p<$ $0.05)$. The mean peak frequency of $\mathrm{MCx}-\mathrm{VM}$ coherence during walking epochs was $35.8 \pm 0.9 \mathrm{~Hz}$ at day $21-28$, which is consistent with our earlier reports of SNpr spike-LFP dominant entrainment frequency during the same behavior (Brazhnik et al., 2014).

In the frequency ranges adjacent to $30-36 \mathrm{~Hz}$, the $18-25$ and $40-50 \mathrm{~Hz}$ ranges, there were no significant increases in total power relative to control during treadmill walking, although there were very modest increases in coherence in the $40-50 \mathrm{~Hz}$ range in the lesion hemisphere between all recorded areas $(\mathrm{MCx}-$ SNpr, $p<0.05$; MCx-VM, $p<0.001$; SNpr-VM, $p<0.05)$.

Consistent with previous observations (Brazhnik et al., 2012), high beta $\mathrm{MCx}-\mathrm{SNpr}$ coherence was also increased in the lesioned hemisphere relative to control $(p<0.001, n=13$ and 8 rats; Fig. 2D). Interestingly, whereas increases in VM LFP power and coherence with SNpr and MCx in the 30-36 Hz range were clearly evident during treadmill walking, as discussed above, coherence between MCX and SNpr LFPs was approximately twice as large as that between VM and MCx or SNpr LFPs. In addition, VM LFP power in the $30-36 \mathrm{~Hz}$ range was lower than that in SNpr and MCx $(p<0.05)$. Although these relative differences in total power and coherence in the high beta range remain to be further explored, the present results show that synchronized activity is highly expressed in the high beta range in the VM during walking and is coherent with the analogous synchronized activity in the SNpr and MCx. Data support the hypothesis that the VM participates in the transmission of exaggerated activity from the $B G$ to the MCx in PD.

\section{Temporal relationships between spikes in $\mathrm{MCx}, \mathrm{SNpr}$, and VM in the dopamine-cell-lesioned hemisphere}

To explore the hypothesis that coherent LFP activity in the BG-thalamocortical circuit reflects sequential spiking activity between the components of the circuit, we examined the temporal relationships between synchronized spikes in the $\mathrm{MCx}, \mathrm{SNpr}$, and VM of the lesioned hemisphere during epochs of treadmill walking (Fig. 3). This was accomplished by first identifying epochs with spikes significantly correlated to their regional LFP oscillations in the $30-36 \mathrm{~Hz}$ range (Fig. $3 A$ ). These spikes and the corresponding LFPs were used to create STWAs for each of two epochs of treadmill walking (MCx, $n=146$ STWAs from 78 spike trains, 19 rats; SNpr, $n=100$ STWAs from 50 spike trains, 12 rats; $\mathrm{VM}, n=130$ STWAs from 67 spike trains, 15 rats, for epochs with firing rates $>2.0 \mathrm{~Hz}$ ). The results show that $29 \%$ of $\mathrm{MCx}, 46 \%$ of SNpr, and $82 \%$ of VM spike trains had epochs with rates $>2 \mathrm{~Hz}$ that were significantly correlated to their respective LFPs in the lesioned hemisphere.

Next, STWAs were constructed from these spike trains in MCx, SNpr, and VM and a simultaneously recorded MCx LFP, band-pass filtered to $30-36 \mathrm{~Hz}$. The cortical 30-36 Hz LFP oscillation was thus used as a common temporal reference to establish relative timing between spiking activity in each area. Overall, the majority of spike trains showing significant spike-LFP relationships with their regional LFPs were also significantly correlated to the cortical 30-36 Hz LFP oscillations (SNpr, 40\%; VM, 65\%).

Analysis showed that spikes in the MCx, SNpr, and VM in the lesioned hemisphere were, on average, occurring at different sequential times points with respect to positive and negative components of the cortical LFP $30-36 \mathrm{~Hz}$ oscillation. Mean phase angles between spikes and cortical LFP oscillations, as assessed by STWAs, were significantly clustered around different phases of the cortical $30-36 \mathrm{~Hz}$ LFP oscillation (MCx, $332 \pm 49.8^{\circ}$, SNpr, $88.8 \pm 56.2^{\circ}, \mathrm{VM}, 302 \pm 56.1^{\circ}, p<0.001$; Fig. $3 A$ ). The dominant frequencies to which spikes in each brain area were correlated within the $30-36 \mathrm{~Hz}$ range showed comparable values: $33.4 \mathrm{~Hz}$ in the MCx, 33.6 Hz in the SNpr, and $33.5 \mathrm{~Hz}$ in the VM. Because the mean dominant frequency from the spike-MCx $30-36 \mathrm{~Hz}$ LFP-derived STWAs is $\sim 33.5 \mathrm{~Hz}$, the duration of typical cortical STWA-based LFP oscillations (peak-to-peak) would be $\sim 30 \mathrm{~ms}$. The temporal relationships between spiking in the three brain regions were estimated using the relative differences in mean phase angles. The phase angle between MCx and SNpr neurons shows a difference of $117^{\circ}$, which corresponds to $9.7 \mathrm{~ms}$, and suggests multisynaptic connectivity between these two regions. The difference in mean phase angle between SNpr and VM spiking of $213^{\circ}$ is equivalent to $18 \mathrm{~ms}$ and would appear compatible with the time that might be required for the VM neurons to recover from synchronized inhibition induced by GABAergic input from the SNpr. The phase difference between VM and $\mathrm{MCx}$ spiking of $30^{\circ}$, corresponding to $2.5 \mathrm{~ms}$, is consistent with direct excitatory connections between these two regions (Fig. 3 ).

\section{Effect of picrotoxin infusion into VM on LFP activity in the BG-thalamocortical circuit}

To evaluate the role of the VM in propagating the synchronized beta activity in the BG-thalamocortical circuit and to determine whether the rhythmic inhibitory input from the BG output nucleus, the SNpr, contributes to the entrainment of VM spiking activity in the high beta range after dopamine cell loss, picrotoxin, a $\mathrm{GABA}_{\mathrm{A}}$ receptor antagonist ( $50 \mathrm{ng}$ in $0.5 \mu \mathrm{l}$ ), was microinjected via a cannula in the VM to reduce the impact of GABAergic input to the VM (Fig. 4). In five rats, picrotoxin was infused into the $\mathrm{VM} \sim 24 \mathrm{~h}$ after infusion of muscimol (see below) and two additional rats were treated in reversed order. There was no difference in response to the order of treatments in changes observed in the $30-36 \mathrm{~Hz}$ LFP power in the SNpr and MCx or in MCx-SNpr coherence during treadmill walking between the two groups.

Microinjection of picrotoxin into the VM significantly reduced 30-36 Hz range MCx and SNpr LFP power and MCxSNpr coherence. LFP power was significantly attenuated at 10 and $30 \mathrm{~min}$ after injection in the SNpr and MCx $(p<0.05)$ during treadmill walking (Fig. $4 A-C$ ). The decreases in MCx and SNpr LFP power at 10 and 30 min after injection were accompanied by notable increases in peak frequency in the LFP spectral power in both $\mathrm{MCx}(35.2 \pm 1.0 \mathrm{~Hz}$ at $10 \mathrm{~min}$ and $36.8 \pm 0.5 \mathrm{~Hz}$ at $30 \mathrm{~min}$ relative to $33.1 \pm 0.5 \mathrm{~Hz}$ in baseline, $p<0.05, n=7$ ) and $\mathrm{SNpr}(38.7 \pm 0.8 \mathrm{~Hz}$ at $10 \mathrm{~min}$ and $36.7 \pm 0.5 \mathrm{~Hz}$ at $30 \mathrm{~min}$ after injection relative to $32.6 \pm 0.6 \mathrm{~Hz}$ in baseline, $p<0.05$, $n=7)$. LFP power in the MCx and SNpr returned to baseline levels by $1 \mathrm{~h}$ after injection (Fig. 4). MCx-SNpr coherence in the high beta range also was significantly attenuated relative to baseline at 10 and $30 \mathrm{~min}(p<0.001)$, but was not significantly different from baseline at $1-2 \mathrm{~h}$ after picrotoxin administration (Fig. 4B). 
A
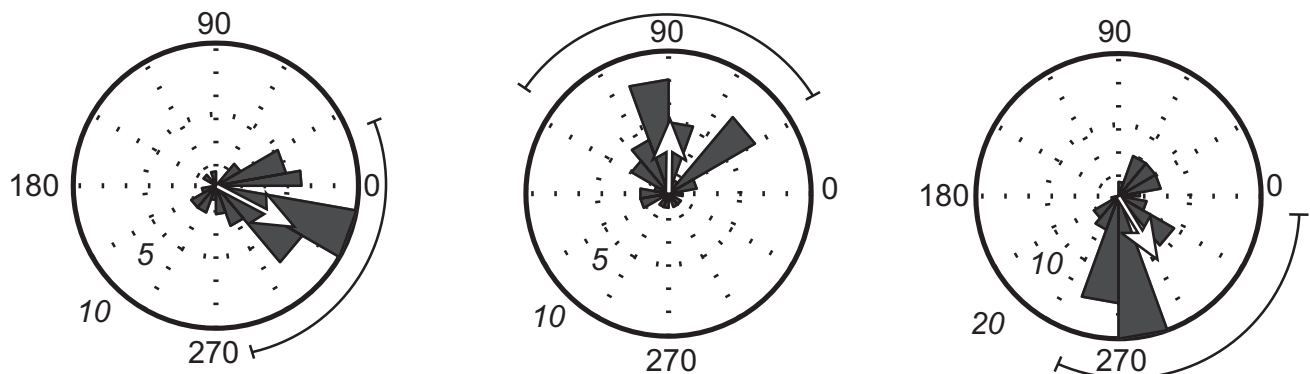

\begin{tabular}{|c|c|c|}
\hline MCX & SNpr & VM \\
\hline $\begin{array}{c}\text { MCx spikes: } \\
29 \% \text { correlated to MCx LFP }\end{array}$ & $\begin{array}{c}\text { SNpr spikes: } \\
46 \% \text { correlated to SNpr LFP }\end{array}$ & $\begin{array}{l}\text { VM spikes: } \\
82 \% \text { correlated to VM LFP }\end{array}$ \\
\hline $\mathrm{N} / \mathrm{A}$ & $\begin{array}{c}\text { SNpr spikes: } \\
40 \% \text { correlated to MCx LFP }\end{array}$ & $\begin{array}{l}\text { VM spikes: } \\
65 \% \text { correlated to MCx LFP }\end{array}$ \\
\hline
\end{tabular}

Sequential Spike Timing

B
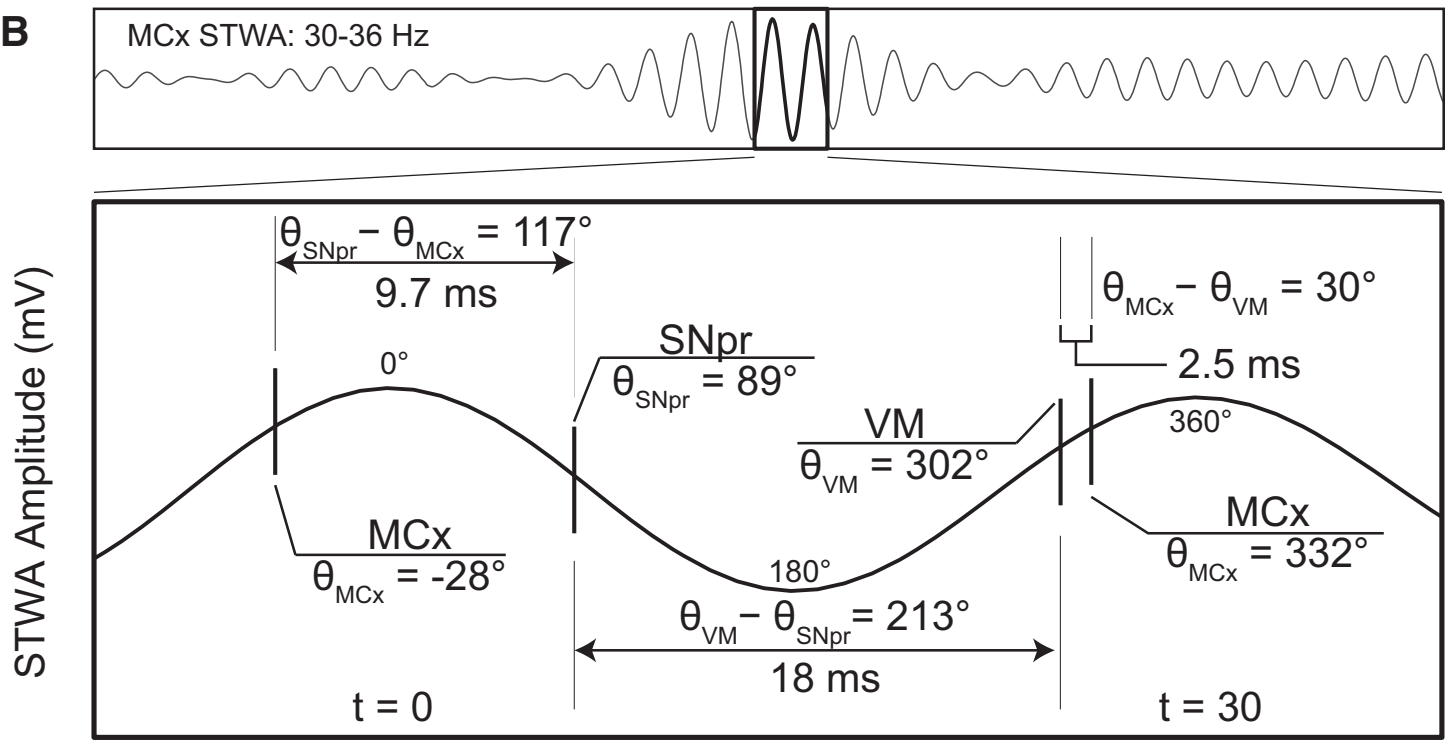

Time (ms)

Figure 3. Relationships of spike trains in the $M C x, V M$, and SNpr to MCx LFPs band-pass filtered in the 30 - $36 \mathrm{~Hz}$ range in recordings from the lesioned hemisphere in hemiparkinsonian rats during treadmill walking. $A$, Polar plots showing the distributions of phases of STWAs from correlated spike trains ( 2 epochs/ spike train) with firing rates $>2 \mathrm{~Hz}$ in the MCX, SNpr, and VM (43STWAs in MCX, left; 40 STWAs in SNpr, middle; 85 STWAs in VM, right) exhibiting significant correlations with the $30-36 \mathrm{~Hz}$ range cortical LFPs. Spikes are significantly oriented to the $30-36 \mathrm{~Hz}$ cortical LFP oscillation in all three regions and the mean phase for each region is significantly different from the other two (Rayleigh, $p<0.001$ ). The strength of the mean phase values normalized to the radius of the circular plot is indicated by arrows. Table below shows the proportion of spike trains in the MCX,SNpr, and VM significantly phase locked to the local and cortical LFP band-pass filtered to the $30-36 \mathrm{~Hz}$ frequency range. $\boldsymbol{B}$, Top, Representative MCX STWA. Bottom, Temporal relationships of representative spike trains in each region with the $30-36 \mathrm{~Hz}$ cortical LFPs. LFP peak was used as zero time point.

Infusion of picrotoxin into the VM significantly affected the firing rates of MCx pyramidal neurons in the lesioned hemisphere. Examination of pyramidal neurons with firing rates $>2$ $\mathrm{Hz}$ showed that during treadmill walking most (92\%) exhibited an increase in rate of $>20 \%$ over baseline. The firing rates of $\mathrm{MCx}$ neurons significantly increased from $6.4 \pm 0.8 \mathrm{~Hz}$ to $11.0 \pm 1.5$ $\mathrm{Hz}(p<0.001, n=13$ cells, Wilcoxon signed-rank test) at 20-29 min after the administration of picrotoxin ( $n=6$ rats).

Importantly, the observed reduction in high beta LFP power in $\mathrm{MCx}$ and SNpr and high beta MCX-SNpr coherence after injection of picrotoxin into the VM was associated with an apparent alleviation of motor symptoms and significant improvement in treadmill walking performance. Contraversive walking in the treadmill was substantially less impaired after the injection of picrotoxin into the VM. Rats showed significant improvement in walking in the contraversive direction at 10 and $30 \mathrm{~min}$ after infusion ( $p<0.001$; Fig. $4 D)$ and in/out step ratios were not significantly different from those during ipsiversive walking at the same 10 and $30 \mathrm{~min}$ time points. By $1-1.5 \mathrm{~h}$ after infusion of picrotoxin, motor deficits had returned to baseline levels, showing the same time course as the recovery of 30-36 $\mathrm{Hz} \mathrm{MCx}$ and SNpr power and $\mathrm{MCx}-\mathrm{SNpr}$ coherence. These results suggest that blockade of rhythmic inhibitory input to the VM from the SNpr leads to substantial reduction in synchronized and phaselocked spiking activity in the VM, which in turn leads to a dramatic reduction in $30-36 \mathrm{~Hz}$ LFP power in the MCx and in the 

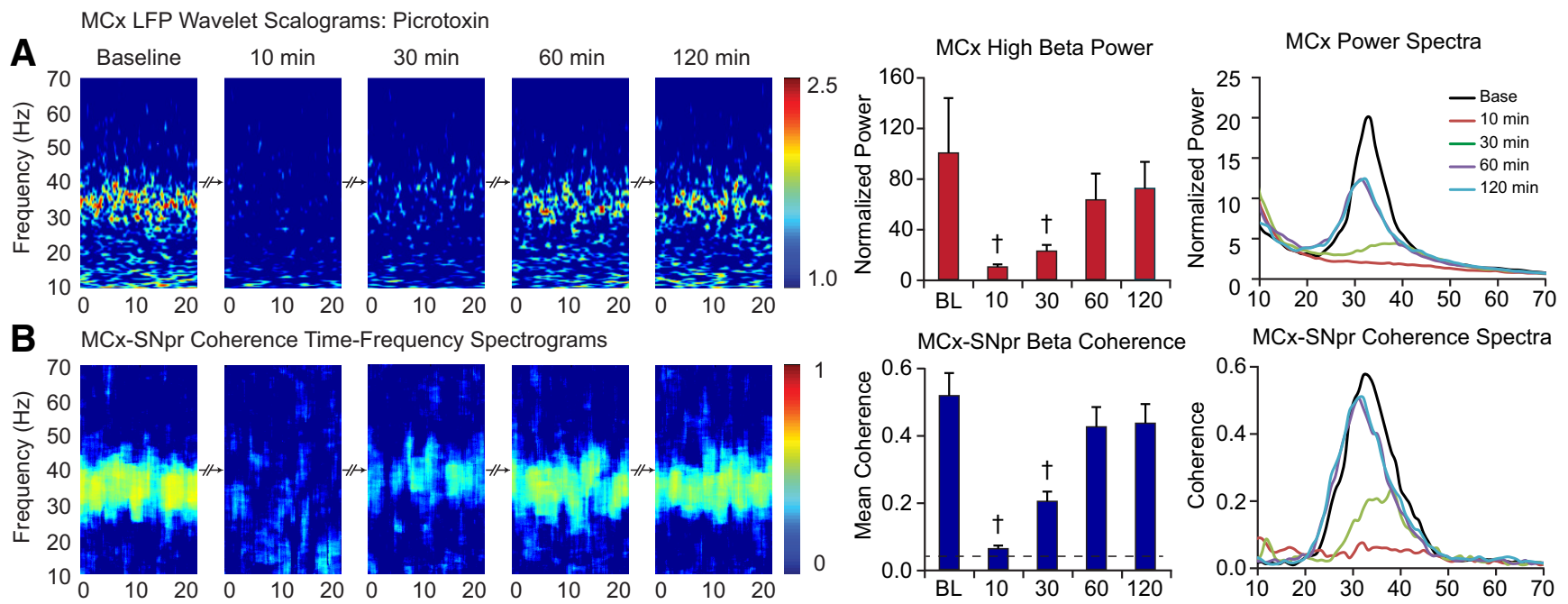

C SNpr LFP Wavelet Scalograms
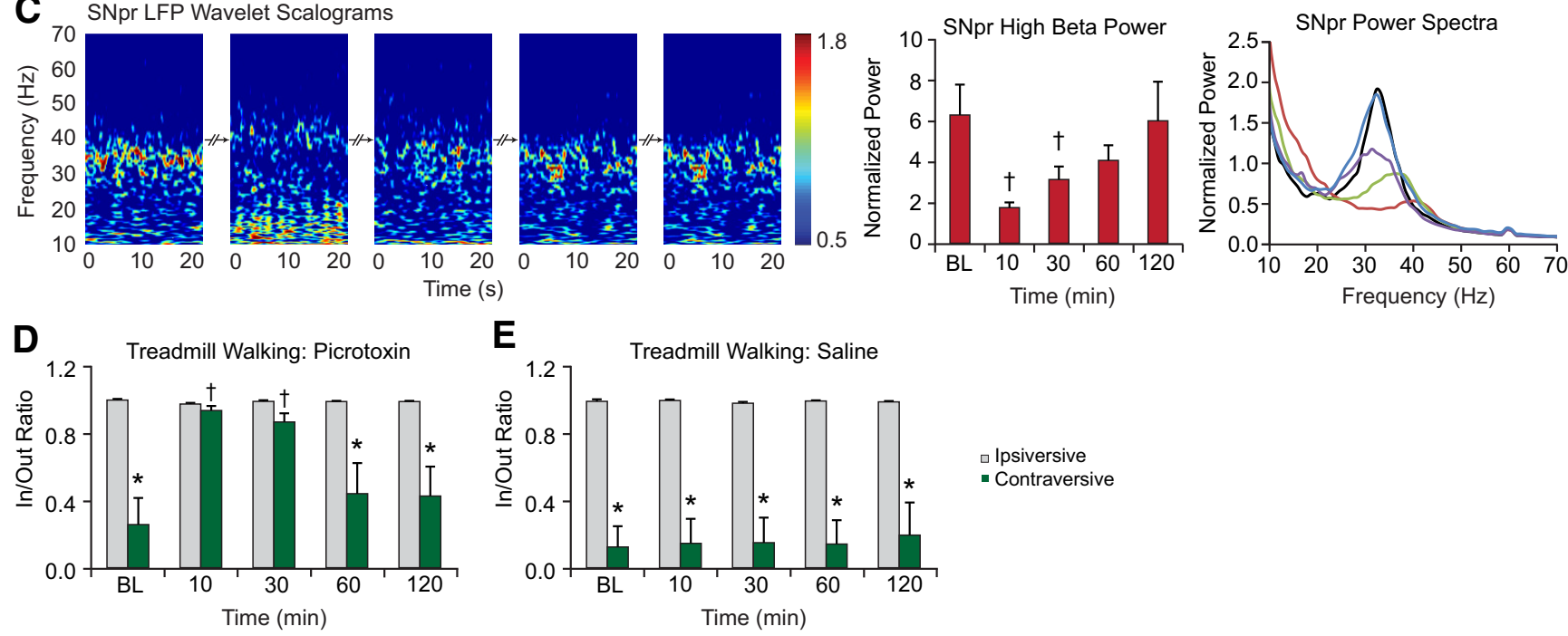

- Ipsiversive
- Contraversive

Figure 4. Effect of picrotoxin infusion into the VM thalamus on LFP oscillations in the MCx and SNpr of the dopamine cell-lesioned hemisphere during treadmill walking. $A-C$, Wavelet-based scalograms of LFP spectral power (left) in the $\operatorname{MCX}(\boldsymbol{A})$ and $\mathrm{SNpr}(\boldsymbol{C})$ and the $\mathrm{MCX}$-SNpr FFT-based coherence (B). Recordings were made during baseline treadmill walking and after $10 \mathrm{~min}, 30 \mathrm{~min}$, and up to $2 \mathrm{~h}$ after infusion of picrotoxin into the VM of the lesioned hemisphere $(n=7,50 \mathrm{ng} / 0.5 \mu \mathrm{ll}$ ). Bar graphs (middle) show MCX and SNpr LFP total normalized power and MCX-SNpr coherence (mean \pm SEM) before and after picrotoxin infusion. The plots and scalograms indicate that infusion of picrotoxin into VM significantly reduces cortical and SNpr $30-36 \mathrm{~Hz}$ range LFP power and their coherence in the lesioned hemisphere $(p<0.05)$. LFP power and $M C x-S N p r$ coherence show recovery to baseline levels within $1 \mathrm{~h}$ after picrotoxin infusion. Plots in the right panel represent averaged power spectra and $M C X-S N p r$ coherence before and after picrotoxin infusion. $\boldsymbol{D}, \boldsymbol{E}$, Bar graphs representing step count ratios for the inner to outer hind limbs during ipsiversive (gray bars) and contraversive (green bars) walking before and after infusion of picrotoxin $(\boldsymbol{D})$ or saline $(\boldsymbol{E})$ into the VM. Infusion of picrotoxin significantly improved contraversive walking in the hemiparkinsonian rats within $30 \mathrm{~min}$ after treatment, as reflected by increases in contraversive step ratios at 10 and $30 \mathrm{~min}(p<0.001)$. Saline injected into the left VM did not affect LFP activity in the MCX and SNpr (data not shown), nor did it significantly alter treadmill walking during the same time points (E). * Significant difference between the ratio of steps in contraversive relative to ipsiversive walking. †Significant difference from baseline.

BG circuit (including the SNpr) in conjunction with the improvement of motor function (walking).

Infusion of the vehicle (saline, $0.5 \mu \mathrm{l}$ ) into the VM did not affect the coherent $30-36 \mathrm{~Hz}$ abnormal LFP oscillatory activity in the MCx or SNpr nor high beta MCx-SNpr coherence $(p>0.05$, data not shown), nor did it improve the impaired contraversive walking in the hemiparkinsonian rats or have any modulatory effect on LFP power and treadmill walking task in control rats $(n=5$; Fig. $4 E)$.

Therefore, the results indicate that blockade of inhibitory input into the VM dramatically diminishes $30-36 \mathrm{~Hz}$ oscillatory activity in the BG-thalamocortical circuit in conjunction with reduction of motor deficit symptoms in a hemiparkinsonian rat.
Effect of muscimol infusion into VM on LFP activity in the BG-thalamocortical circuit

To further confirm the role of the VM in mediating the propagation of synchronized activity in the BG-thalamocortical circuit, the $\mathrm{GABA}_{\mathrm{A}}$ receptor agonist muscimol $(40 \mathrm{ng}$ in $0.5 \mu \mathrm{l})$ was infused into the VM to temporarily reduce VM activity while LFPs and spiking activity were recorded in SNpr and MCx from rats walking on the circular treadmill (Fig. 5). Wavelet-based time-frequency scalograms in Figure 5, $A-C$, left, display the striking loss of high beta range oscillations in the $\mathrm{MCx}$ and $\mathrm{SNpr}$ and the lack of $\mathrm{MCx}-\mathrm{SNpr}$ coherence at $1 \mathrm{~h}$ after muscimol infusion. These oscillations show a partial recovery with a lower peak frequency in the spectrograms of both LFP power and $\mathrm{MCx}-$ $\mathrm{SNpr}$ coherence at $3 \mathrm{~h}$ after injection and nearly complete recov- 

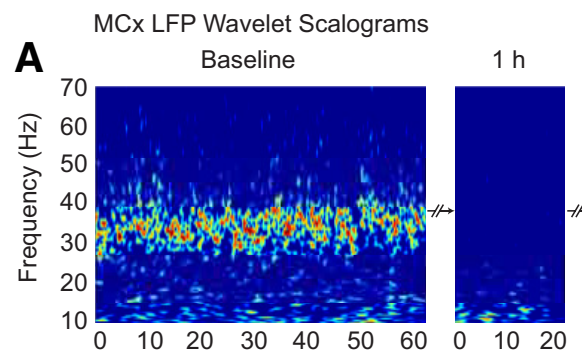

\section{Muscimol}
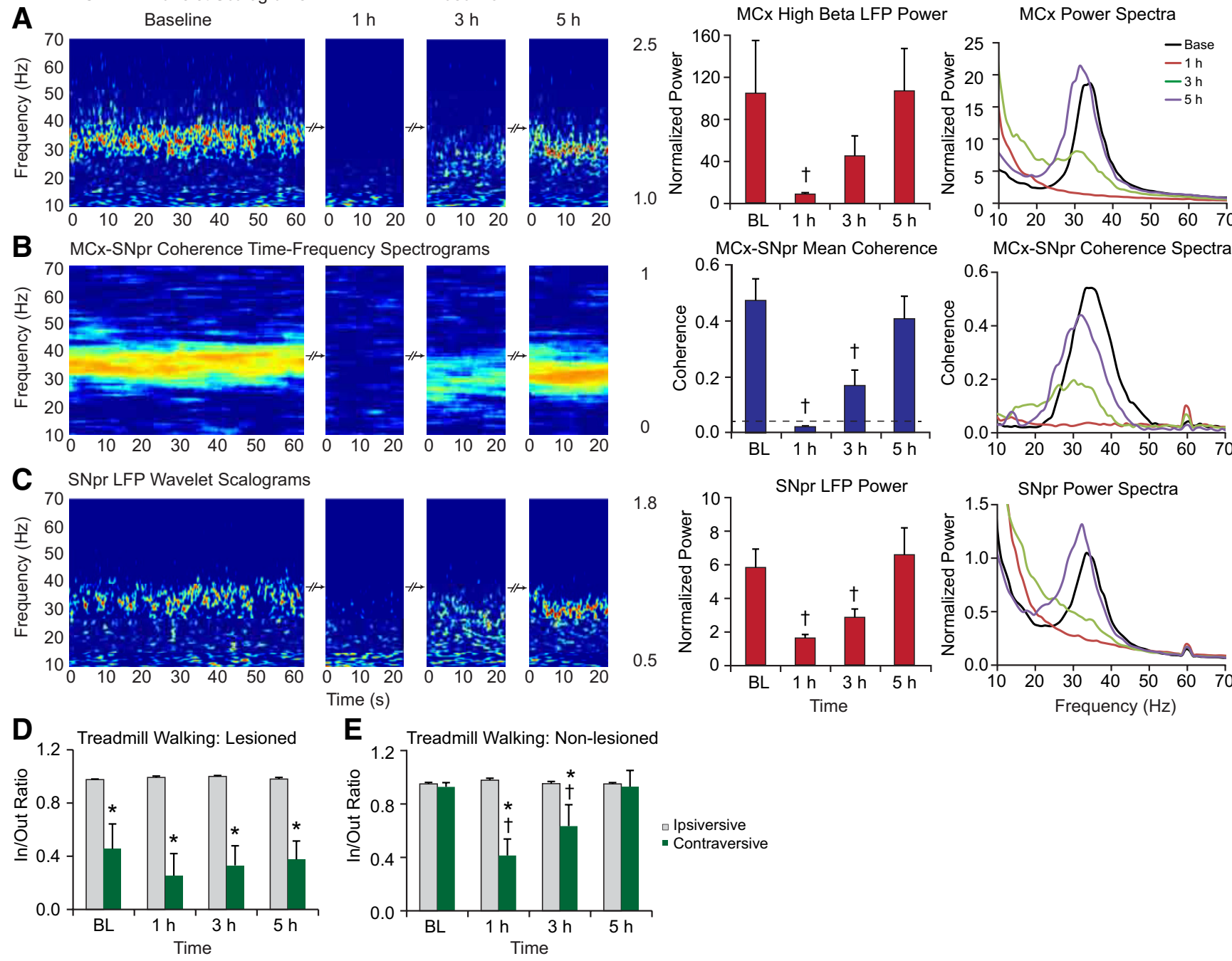

Figure 5. Effect of muscimol infusion into the VM thalamus on the LFP oscillations in the MCx and SNpr in control and dopamine cell-lesioned rats during treadmill walking. $\boldsymbol{A}$-C, Wavelet-based scalograms of LFP spectral power (left) in the MCX $(\boldsymbol{A})$ and $\mathrm{SNpr}(\boldsymbol{C})$ and the $\mathrm{MCX}$-SNpr FFT-based coherence $(\boldsymbol{B})$. Recordings were made during baseline (BL) treadmill walking and after $1-5 \mathrm{~h}$ after infusion of muscimol into the VM in the lesioned hemisphere $(n=6,40 \mathrm{ng} / 0.5 \mu \mathrm{l}$ ). Bar graphs (middle) show MCX and SNpr LFP total normalized power and their coherence (mean \pm SEM) before and after $1-5 \mathrm{~h}$ of muscimol administration into the VM. The plots and scalograms indicate that infusion of muscimol into the VM significantly reduces MCx and SNpr $30-36 \mathrm{~Hz}$ range LFP power ( $p<$ $0.05)$ and $M C X-S N p r$ coherence $(p<0.001)$ in the lesioned hemisphere at $1 \mathrm{~h}$. LFP power and MCX-SNpr coherence gradually returns to baseline levels over $5 \mathrm{~h}$ after treatment. Plots in the right panel represent averaged power spectra and $M C X-S N p r$ coherence before and after muscimol infusion. $\boldsymbol{D}, \boldsymbol{E}$, Bar graphs representing step count ratios for the inner to outer hind limbs during ipsiversive (gray bars) and contraversive (green bars) walking in lesioned $(\boldsymbol{D})$ and control $(\boldsymbol{E})$ rats before and after infusion of muscimol. Infusion of muscimol into the VM does not notably alter impaired gait in lesioned rats. Muscimol injected into the left VM in the control rats $(n=4)$ dramatically reduces step ratios in contraversive walking at 1 and $3 \mathrm{~h}$ after injection $(p<0.003)$. *Significant difference between the ratio of steps in contraversive relative to ipsiversive walking. TSignificant difference from baseline.

ery of the 30-36 Hz LFP power and MCx-SNpr coherence at $5 \mathrm{~h}$. LFPs in four of five rats exhibited spindling activity during treadmill walking in both MCx and SNpr recorded during the third hour after muscimol injection. Statistical analysis of high beta range power and coherence in hour 3 recordings were conducted on epochs with minimal incidents of spindles.

One hour after muscimol infusion, mean MCX and SNpr LFP power and $\mathrm{MCx}-\mathrm{SNpr}$ coherence in the $30-36 \mathrm{~Hz}$ range were significantly attenuated relative to baseline $(p<0.05$ for SNpr and $\mathrm{MCx}$ power, $n=5, p<0.001$ for $\mathrm{MCx}-\mathrm{SNpr}$ coherence, $n=5)$. Mean $30-36 \mathrm{~Hz}$ range MCx and SNpr LFP power and coherence were increased at $3 \mathrm{~h}$ after infusion, but were still considerably reduced relative to baseline values (Fig. $5 A-C$, middle). The peak frequency of high beta $\mathrm{MCx}-\mathrm{SNpr}$ coherence and $\mathrm{MCx}$ and SNpr LFP spectral power were lower compared with baseline (peak frequency of SNpr LFP power: $26.9 \pm 3.4 \mathrm{~Hz}$ at $3 \mathrm{~h}$ vs
$33.8 \pm 0.9 \mathrm{~Hz}$ in baseline, $p<0.05$; peak frequency of MCx LFP power: $30.6 \pm 0.9 \mathrm{~Hz}$ at $3 \mathrm{~h}$ vs $34.6 \pm 0.5 \mathrm{~Hz}$ in baseline, $p<0.05$; peak frequency of MCx-SNpr coherence: $30.4 \pm 0.5 \mathrm{~Hz}$ at $3 \mathrm{~h}$ vs $35.3 \pm 1.1 \mathrm{~Hz}$ in baseline, $p<0.01)$. Five hours after muscimol administration, high beta LFP power and $\mathrm{MCx}-\mathrm{SNpr}$ coherence returned to levels not significantly different from baseline, although peak beta frequency in the power and coherence spectra remained lower relative to the peaks in baseline (MCx LFP power: $32.2 \pm 1.1 \mathrm{~Hz}, p=0.06$; SNpr LFP power: $32.2 \pm 1.1 \mathrm{~Hz}, p<$ 0.05; MCx-SNpr coherence: $32.2 \pm 1.1 \mathrm{~Hz}, p<0.05$; Fig. $5 \mathrm{~A}-\mathrm{C}$, right).

Infusion of muscimol into the VM had the opposite effect on the firing rates of $\mathrm{MCx}$ layer 5/6 pyramidal neurons relative to picrotoxin. In lesioned and control rats during ipsiversive walking, most layer $5 / 6$ pyramidal neurons firing $>2 \mathrm{~Hz}$ showed a decrease in rate of $>20 \%$ from preinfusion walking epochs $(93 \%$ 
and $85 \%$, respectively, for lesioned and control). On average, rates of these MCx pyramidal neurons significantly decreased from $8.0 \pm 1.4 \mathrm{~Hz}$ to $1.3 \pm 0.4 \mathrm{~Hz}(p<0.001$, paired $t$ test, $n=$ 13 cells, 2 epochs per spike trains, $n=4$ rats) $1 \mathrm{~h}$ after the administration of muscimol in lesioned rats and decreased from $7.3 \pm$ $1.2 \mathrm{~Hz}$ to $4.3 \pm 1.2 \mathrm{~Hz}(p<0.003$, paired $t$ test, $n=13$ spike trains, 2 epochs per spike train) in control rats $(n=4)$.

The effects of muscimol microinjections on motor performance in both unilaterally lesioned and intact rats were assessed by examining stepping activity during walking in the circular treadmill (see Materials and Methods). The results show that infusion of muscimol into the VM of intact animals produces a deficit in contraversive walking (Fig. $5 E$ ) similar to that seen in unilaterally lesioned rats before and after muscimol (Fig. 5D). The in/out step ratio in control rats during treadmill walking in the contraversive direction was significantly smaller than during walking in the ipsiversive direction at 1 and $3 \mathrm{~h}(p<0.001, n=5)$ after infusion and returned to baseline levels by $5 \mathrm{~h}$. In the unilaterally dopamine cell-lesioned rats, contraversive walking remained impaired and stepping ratios were not significantly different from baseline after muscimol infusion ( $p>0.05, n=5)$. As in baseline, the in/out ratio of steps was significantly smaller during walking in the contraversive direction than in the ipsiversive direction at baseline $(p<0.05), 1 \mathrm{~h}(p<0.01), 3 \mathrm{~h}(p<$ $0.05)$, and $5 \mathrm{~h}(p<0.05)$ after muscimol infusion, whereas the in/out ratio during walking in the contraversive direction did not vary between these time points.

Therefore, the use of muscimol injections to reduce activity in the VM provided additional evidence for a critical role of the VM in facilitating transmission of the beta-range activity throughout the thalamocortical-BG loop. Moreover, because this procedure also induced walking deficits in the intact rat, an observation consistent with results from other studies (Starr and Summerhayes, 1983a; Starr and Summerhayes, 1983b; Klockgether et al., 1985), the results further show that these motor deficits are not critically dependent on the presence of oscillatory activity in this loop.

\section{Discussion}

The present study provides a series of observations supporting the view that the VM thalamic nucleus is a critical part of the network contributing to the emergence of the exaggerated highbeta range oscillatory activity in the $\mathrm{MCx}$ and $\mathrm{BG}$ of the hemiparkinsonian rat during treadmill walking. The transition from inattentive rest to treadmill walking induced an increase in high beta range $(30-36 \mathrm{~Hz})$ activity in the VM thalamus of the dopamine cell-lesioned hemisphere relative to the nonlesioned hemisphere. This was accompanied by increases in the synchronization of VM spikes to the local and cortical high beta LFP activity and increased coherence between LFP activity in the VM, $\mathrm{MCx}$ and SNpr in the same frequency range. In addition, high beta range LFP power and coherence in the MCx and SNpr were dramatically reduced by blocking $\mathrm{GABA}_{\mathrm{A}}$ receptor-mediated input into the VM through infusion of the $\mathrm{GABA}_{\mathrm{A}}$ antagonist picrotoxin or by inhibiting VM activity through local infusion of the $\mathrm{GABA}_{\mathrm{A}}$ agonist muscimol. Collectively, these observations show that alterations in the activity of the VM neurons are tightly correlated with the expression of exaggerated high beta activity in the $\mathrm{MCX}-\mathrm{BG}$ circuit after loss of dopamine.

The substantial and coherent increases in high beta range LFP activity in the VM, SNpr, and MCx of the dopamine cell-lesioned hemisphere during treadmill walking observed in the present study are consistent with previous reports of increases in high beta activity in the MCx and SNpr (Avila et al., 2010; Brazhnik et al., 2012; Brazhnik et al., 2014) and STN (Delaville et al., 2015) in the same rat model. Similar increases in LFP power emerge at slightly lower frequencies $(\sim 28 \mathrm{~Hz})$, when the rats are alert and attentive but not actively moving (Brazhnik et al., 2014). In contrast, significant high beta LFP peaks are not evident in these brain areas during periods of inattentive rest (Brazhnik et al., 2012; Brazhnik et al., 2014; Delaville et al., 2015). Although the overall frequency range of exaggerated LFP high beta synchronization evident in the alert and active hemiparkinsonian rat $(30-36 \mathrm{~Hz})$ is higher than that typically observed in the PD patient (Levy et al., 2002; Brown, 2003; Priori et al., 2004; AlonsoFrech et al., 2006; Kühn et al., 2009), the state-dependent nature of this activity, its responsiveness to L-DOPA treatment, and evidence of amplitude modulation during movement (Brazhnik et al., 2012; Brazhnik et al., 2014; Delaville et al., 2015) suggest that this activity may be driven by processes relevant to those inducing synchronized beta-range oscillations in the BG and MCx of the PD patient.

Anatomical studies have shown that the VM thalamic nucleus is one of the main targets of BG output in the rat (Beckstead et al., 1979; Di Chiara et al., 1979; Herkenham, 1979; Deniau and Chevalier, 1992; Kuramoto et al., 2011). The VM, in turn, projects most extensively to layers I and II of the MCx and anterior cingulate cortex (Arbuthnott et al., 1990; Clascá et al., 2012; Kuramoto et al., 2015). The comparable BG-receiving thalamic nuclei in the primate are the ventral anterior pars magnocellularis and medial dorsal nuclei (Ilinsky and Kultas-Ilinsky, 2002; McFarland and Haber, 2002; Haber and Calzavara, 2009). Our results support the view that, after loss of dopamine, the BGreceiving nuclei of the motor thalamus become an important route through which highly synchronized and oscillatory activity in $B G$ output nuclei is transmitted to the $\mathrm{MCx}$, thus enabling the ongoing expression of this activity in the BG thalamocortical circuit.

The mechanisms underlying the exaggerated expression of oscillatory activity in the $\mathrm{BG}$ network of $\mathrm{PD}$ patients remain a matter of considerable interest and debate, as does the functional significance of this activity (Hammond et al., 2007; Eusebio and Brown, 2009; Ellens and Leventhal, 2013; Quiroga-Varela et al., 2013; Stein and Bar-Gad, 2013; Brittain and Brown, 2014; Galvan et al., 2015; Nambu et al., 2015). A number of studies involving neurophysiological analysis and/or computational modeling have focused on reciprocal activity within the STN-external globus pallidus (GPe) circuitry in conjunction with input from the hyperdirect pathway from cortex to STN in giving rise to the beta oscillations (Bevan et al., 2002; Bevan et al., 2006; Mallet et al., 2008; Holgado et al., 2010; Tachibana et al., 2011; Pavlides et al., 2012; Abdi et al., 2015). However, other studies have addressed the emergence and properties of these oscillations in the context of the larger BG-thalamocortical loop (Leblois et al., 2006; Moran et al., 2011; Rubin et al., 2012; Kang and Lowery, 2013; Santaniello et al., 2015). Indeed, the involvement of the thalamocortical projection is supported by the current evidence that alterations in VM activity induced by infusion of the $\mathrm{GABA}_{\mathrm{A}}$ antagonist picrotoxin or the $\mathrm{GABA}_{\mathrm{A}}$ agonist muscimol dramatically reduces the high beta range oscillatory activity in both the MCX and SNpr, as well as the coherence between MCX and SNpr LFP during treadmill walking. Although both picrotoxin and muscimol had similar effects on beta-range activity in $\mathrm{MCx}$ and SNpr when infused into the VM, their effects on firing rates of layer 5/6 pyramidal neurons in the $\mathrm{MCx}$ and on motor behavior were different. Infusion of picrotoxin, $\mathrm{GABA}_{\mathrm{A}}$ receptor blocker, 
induced a modest increase in cortical firing rates and facilitated treadmill walking in the contraversive direction in the hemiparkinsonian rat. In contrast, increased $\mathrm{GABA}_{\mathrm{A}}$ receptor stimulation in the VM via muscimol infusion was associated with a reduction in cortical firing rates and the perseverance of motor deficits in treadmill walking in the hemiparkinsonian rat, as well as the temporary emergence of motor deficits in the intact rat.

To further explore the idea that loss of dopamine might facilitate rhythmic activity within the BG thalamocortical circuit through sequential entrainment of spiking within different nodes of the circuit, we determined whether the sum of the delays between spikes that were significantly correlated to LFPs in the $\mathrm{SNpr}, \mathrm{VM}$, and $\mathrm{MCx}$ was comparable to the period of the cortical LFP high beta range oscillation. The mean spike latency between the SNpr and VM, calculated from STWA-derived phase lags, was $\sim 18 \mathrm{~ms}$, which would appear sufficient for VM spiking to recover from the inhibition induced by synchronized GABAergic input from the SNpr. In contrast, the latency between spiking in the $\mathrm{VM}$ and spiking of the pyramidal neurons in layers $5 / 6$ was much shorter, on the order of $2.5 \mathrm{~ms}$, consistent with the monosynaptic excitatory connection between VM and MCx. Timing between cortical spiking and SNpr-correlated activity was $\sim 9.7 \mathrm{~ms}$. Overall, consideration of the sum of these intervals suggests that sequential entrainment of activity from SNpr to VM to MCx to SNpr would take $\sim 30 \mathrm{~ms}$, which is consistent with the idea that recurrent entrainment within this circuit could produce a sustained $33 \mathrm{~Hz}$ rhythm.

There remain many questions, however, about the role of the $\mathrm{MCx}$ and the relative contributions of activity in the STN-GPe network in transmission of the high beta rhythm to downstream sites. The present results predicts that SNpr spiking is engaged within $\sim 10 \mathrm{~ms}$ after the cortical neurons respond to thalamic input, but how this transmission is affected by cortical output or resonance within in the STN-GPe subcircuit remains to be seen. Ongoing studies in this hemiparkinsonian rat model have failed to find evidence for substantial synchronization of spiking in striatal medial spiny neurons to this high beta range activity (Cruz et al., 2013). Considerable changes in plasticity have been described at many levels of the BG circuits after loss of dopamine, including in cortico-subthalamic synapses (Chu et al., 2015), STN-GPe interactions (Fan et al., 2012) and subthalamo-nigral synapses (Dupuis et al., 2013; Dupuis et al., 2014). Such widespread and diverse plastic alterations undoubtedly contribute to the emergence of the exaggerated oscillatory activity. Interestingly, mean peak frequency of the high beta activity in MCx and SNpr during treadmill walking gradually increases over a period of weeks at a rate of $\sim 1 \mathrm{~Hz}$ per week (Brazhnik et al., 2012; Brazhnik et al., 2014). This subtle but significant increase in frequency may reflect the net effect of ongoing plasticity in BG circuits after loss of dopamine.

In conclusion, the present results indicate that the VM thalamus, which receives substantial GABAergic innervation from the SNpr and subsequently projects to the MCx, plays an important role in transmitting high beta-range synchronous oscillatory activity from the $\mathrm{BG}$ to the MCx. Relationships between cortical output and the reciprocally connected STN-GPe subcircuits remain to be clarified in the context of the generation and frequency of the high beta oscillations. Nevertheless, the present observations show that disruption of these oscillations by either inactivating thalamic neurons with muscimol or blunting the GABAergic input from SNpr reduces expression of the high beta activity in both the $\mathrm{MCx}$ and $\mathrm{BG}$ output. These observations support the idea that loss of dopamine affects the balance of activity throughout the BG-thalamocortical loop facilitating entrainment at a frequency reflecting the time of transmission between interconnected components of this circuit.

\section{References}

Abdi A, Mallet N, Mohamed FY, Sharott A, Dodson PD, Nakamura KC, Suri S, Avery SV, Larvin JT, Garas FN, Garas SN, Vinciati F, Morin S, Bezard E, Baufreton J, Magill PJ (2015) Prototypic and arkypallidal neurons in the dopamine-intact external globus pallidus. J Neurosci 35:6667-6688. CrossRef Medline

Alonso-Frech F, Zamarbide I, Alegre M, Rodríguez-Oroz MC, Guridi J, Manrique M, Valencia M, Artieda J, Obeso JA (2006) Slow oscillatory activity and levodopa-induced dyskinesias in Parkinson's disease. Brain 129: 1748-1757. CrossRef Medline

Arbuthnott GW, MacLeod NK, Maxwell DJ, Wright AK (1990) Distribution and synaptic contacts of the cortical terminals arising from neurons in the rat ventromedial thalamic nucleus. Neuroscience 38 : 47-60. CrossRef Medline

Avila I, Parr-Brownlie LC, Brazhnik E, Castañeda E, Bergstrom DA, Walters JR (2010) Beta frequency synchronization in basal ganglia output during rest and walk in a hemiparkinsonian rat. Exp Neurol 221:307-319. CrossRef Medline

Beckstead RM, Domesick VB, Nauta WJ (1979) Efferent connections of the substantia nigra and ventral tegmental area in the rat. Brain Res 175: 191-217. CrossRef Medline

Bevan MD, Magill PJ, Terman D, Bolam JP, Wilson CJ (2002) Move to the rhythm: oscillations in the subthalamic nucleus-external globus pallidus network. Trends Neurosci 25:525-531. CrossRef Medline

Bevan MD, Atherton JF, Baufreton J (2006) Cellular principles underlying normal and pathological activity in the subthalamic nucleus. Curr Opin Neurobiol 16:621-628. CrossRef Medline

Brazhnik E, Cruz AV, Avila I, Wahba MI, Novikov N, Ilieva NM, McCoy AJ, Gerber C, Walters JR (2012) State-dependent spike and local field synchronization between motor cortex and substantia nigra in hemiparkinsonian rats. J Neurosci 32:7869-7880. CrossRef Medline

Brazhnik E, Novikov N, McCoy AJ, Cruz AV, Walters JR (2014) Functional correlates of exaggerated oscillatory activity in basal ganglia output in hemiparkinsonian rats. Exp Neurol 261:563-577. CrossRef Medline

Brittain JS, Brown P (2014) Oscillations and the basal ganglia: motor control and beyond. Neuroimage 85:637-647. CrossRef Medline

Brown P (2003) Oscillatory nature of human basal ganglia activity: Relationship to the pathophysiology of Parkinson's disease. Mov Disord 18: 357-363. CrossRef Medline

Brown P, Williams D (2005) Basal ganglia local field potential activity: character and functional significance in the human. Clin Neurophysiol 116: 2510-2519. CrossRef Medline

Brown P, Oliviero A, Mazzone P, Insola A, Tonali P, Di Lazzaro V (2001) Dopamine dependency of oscillations between subthalamic nucleus and pallidum in Parkinson's disease. J Neurosci 21:1033-1038. Medline

Cenci MA, Whishaw IQ, Schallert T (2002) Animal models of neurological deficits: how relevant is the rat? Nat Rev Neurosci 3:574-579. CrossRef Medline

Chu HY, Atherton JF, Wokosin D, Surmeier DJ, Bevan MD (2015) Heterosynaptic regulation of external globus pallidus inputs to the subthalamic nucleus by the motor cortex. Neuron 85:364-376. CrossRef Medline

Clascá F, Rubio-Garrido P, Jabaudon D (2012) Unveiling the diversity of thalamocortical neuron subtypes. Eur J Neurosci 35:1524-1532. CrossRef Medline

Cruz AV, Mallet N, Magill PJ, Brown P, Averbeck BB (2009) Effects of dopamine depletion on network entropy in the external globus pallidus. J Neurophysiol 102:1092-1102. CrossRef Medline

Cruz AV, Dupre K, Eyring K, Gerber C, Mccoy A, Delaville C, Walters J (2013) Excessive oscillatory dynamics in the cortico-striato-nigral network in rodent models of Parkinson's disease and L-dopa-induced dyskinesia. Soc Neurosci Abstr 43:648.04/RR2.

Delaville C, Cruz AV, McCoy AJ, Brazhnik E, Avila I, Novikov N, Walters JR (2014) Oscillatory activity in basal ganglia and motor cortex in an awake behaving rodent model of Parkinson's disease. Basal Ganglia 3:221-227. CrossRef Medline

Delaville C, McCoy AJ, Gerber CM, Cruz AV, Walters JR (2015) Subthalamic Nucleus activity in the awake hemiparkinsonian rat: relationships 
with motor and cognitive networks. J Neurosci 35:6918-6930. CrossRef Medline

Deniau JM, Chevalier G (1992) The lamellar organization of the rat substantia nigra pars reticulata-distribution of projection neurons. Neuroscience 46:361-377. CrossRef Medline

Di Chiara G, Morelli M, Porceddu ML, Gessa GL (1979) Role of thalamic gamma-aminobutyrate in motor functions: catalepsy and ipsiversive turning after intrathalamic muscimol. Neuroscience 4:1453-1465. CrossRef Medline

Dupuis JP, Feyder M, Miguelez C, Garcia L, Morin S, Choquet D, Hosy E, Bezard E, Fisone G, Bioulac BH, Baufreton J (2013) Dopaminedependent long-term depression at subthalamo-nigral synapses is lost in experimental parkinsonism. J Neurosci 33:14331-14341. CrossRef Medline

Dupuis JP, Bioulac BH, Baufreton J (2014) Long-term depression at distinct glutamatergic synapses in the basal ganglia. Rev Neurosci 25:741-754. Medline

Ellens DJ, Leventhal DK (2013) Review: electrophysiology of basal ganglia and cortex in models of Parkinson disease. J Parkinsons Dis 3:241-254. Medline

Eusebio A, Brown P (2009) Synchronisation in the beta frequency-band: the bad boy of parkinsonism or an innocent bystander? Exp Neurol 217:1-3. CrossRef Medline

Fan KY, Baufreton J, Surmeier DJ, Chan CS, Bevan MD (2012) Proliferation of external globus pallidus-subthalamic nucleus synapses following degeneration of midbrain dopamine neurons. J Neurosci 32:13718-13728. CrossRef Medline

Galvan A, Devergnas A, Wichmann T (2015) Alterations in neuronal activity in basal ganglia-thalamocortical circuits in the parkinsonian state. Front Neuroanat 9.

Gatev P, Darbin O, Wichmann T (2006) Oscillations in the basal ganglia under normal conditions and in movement disorders. Mov Disord 21: 1566-1577. CrossRef Medline

Haber SN, Calzavara R (2009) The cortico-basal ganglia integrative network: the role of the thalamus 35. Brain Res Bull 78:69-74. CrossRef Medline

Hammond C, Bergman H, Brown P (2007) Pathological synchronization in Parkinson's disease: networks, models and treatments. Trends Neurosci 30:357-364. CrossRef Medline

Herkenham M (1979) Afferent and efferent connections of the ventromedial thalamic nucleus in the rat. J Comp Neurol 183:487-517. CrossRef Medline

Holgado AJ, Terry JR, Bogacz R (2010) Conditions for the generation of beta oscillations in the subthalamic nucleus-globus pallidus network. J Neurosci 30:12340-12352. CrossRef Medline

Ilinsky IA, Kultas-Ilinsky K (2002) Motor thalamic circuits in primates with emphasis on the area targeted in treatment of movement disorders. Mov Disord 17:S9-S14. CrossRef Medline

Kang G, Lowery MM (2013) Interaction of oscillations, and their suppression via deep brain stimulation, in a model of the cortico-basal ganglia network. IEEE Transactions on Neural Systems and Rehabilitation Engineering 21:244-253. CrossRef Medline

Klockgether T, Schwarz M, Turski L, Wolfarth S, Sontag KH (1985) Rigidity and catalepsy after injections of muscimol into the ventromedial thalamic nucleus: an electromyographic study in the rat. Exp Brain Res 58: 559-569. Medline

Kühn AA, Trottenberg T, Kivi A, Kupsch A, Schneider GH, Brown P (2005) The relationship between local field potential and neuronal discharge in the subthalamic nucleus of patients with Parkinson's disease. Exp Neurol 194:212-220. CrossRef Medline

Kühn AA, Kupsch A, Schneider GH, Brown P (2006) Reduction in subthalamic $8-35 \mathrm{~Hz}$ oscillatory activity correlates with clinical improvement in Parkinson's disease. Eur J Neurosci 23:1956-1960. CrossRef Medline

Kühn AA, Tsui A, Aziz T, Ray N, Brücke C, Kupsch A, Schneider GH, Brown P (2009) Pathological synchronisation in the subthalamic nucleus of patients with Parkinson's disease relates to both bradykinesia and rigidity. Exp Neurol 215:380-387. CrossRef Medline

Kuramoto E, Fujiyama F, Nakamura KC, Tanaka Y, Hioki H, Kaneko T (2011) Complementary distribution of glutamatergic cerebellar and GABAergic basal ganglia afferents to the rat motor thalamic nuclei. Eur J Neurosci 33:95-109. CrossRef Medline

Kuramoto E, Ohno S, Furuta T, Unzai T, Tanaka YR, Hioki H, Kaneko T
(2015) Ventral medial nucleus neurons send thalamocortical afferents more widely and more preferentially to layer 1 than neurons of the ventral anterior-ventral lateral nuclear complex in the rat. Cereb Cortex 25: 221-235. CrossRef Medline

Leblois A, Boraud T, Meissner W, Bergman H, Hansel D (2006) Competition between feedback loops underlies normal and pathological dynamics in the basal ganglia. J Neurosci 26:3567-3583. CrossRef Medline

Levy R, Hutchison WD, Lozano AM, Dostrovsky JO (2002) Synchronized neuronal discharge in the basal ganglia of parkinsonian patients is limited to oscillatory activity. J Neurosci 22:2855-2861. Medline

Mallet N, Pogosyan A, Márton LF, Bolam JP, Brown P, Magill PJ (2008) Parkinsonian beta oscillations in the external globus pallidus and their relationship with subthalamic nucleus activity 51. J Neurosci 28:1424514258. CrossRef Medline

McFarland NR, Haber SN (2002) Thalamic relay nuclei of the basal ganglia form both reciprocal and nonreciprocal cortical connections, linking multiple frontal cortical areas. J Neurosci 22:8117-8132. Medline

Mitra PP, Bokil H (2008) Observed brain dynamics. Oxford: OUP.

Moran RJ, Mallet N, Litvak V, Dolan RJ, Magill PJ, Friston KJ, Brown P (2011) Alterations in brain connectivity underlying beta oscillations in parkinsonism. PLoS Comput Biol 7.

Murer MG, Tseng KY, Kasanetz F, Belluscio M, Riquelme LA (2002) Brain oscillations, medium spiny neurons, and dopamine. Cell Mol Neurobiol 22:611-632. CrossRef Medline

Nambu A, Tachibana Y, Chiken S (2015) Cause of parkinsonian symptoms: firing rate, firing pattern or dynamic activity changes? Basal Ganglia 5:1-6. CrossRef

Olsson M, Nikkhah G, Bentlage C, Björklund A (1995) Forelimb akinesia in the rat Parkinson model: differential effects of dopamine agonists and nigral transplants as assessed by a new stepping test. J Neurosci 15:3863-3875. Medline

Pavlides A, Hogan SJ, Bogacz R (2012) Improved conditions for the generation of beta oscillations in the subthalamic nucleus-globus pallidus network. Eur J Neurosci 36:2229-2239. CrossRef Medline

Priori A, Foffani G, Pesenti A, Tamma F, Bianchi AM, Pellegrini M, Locatelli M, Moxon KA, Villani RM (2004) Rhythm-specific pharmacological modulation of subthalamic activity in Parkinson's disease. Exp Neurol 189:369-379. CrossRef Medline

Quiroga-Varela A, Walters JR, Brazhnik E, Marin C, Obeso JA (2013) What basal ganglia changes underlie the parkinsonian state? The significance of neuronal oscillatory activity. Neurobiol Dis 58:242-248. CrossRef Medline

Rubin JE, McIntyre CC, Turner RS, Wichmann T (2012) Basal ganglia activity patterns in parkinsonism and computational modeling of their downstream effects. Eur J Neurosci 36:2213-2228. CrossRef Medline

Santaniello S, McCarthy MM, Montgomery EB Jr, Gale JT, Kopell N, Sarma SV (2015) Therapeutic mechanisms of high-frequency stimulation in Parkinson's disease and neural restoration via loop-based reinforcement. Proc Natl Acad Sci U S A 112:E586-E595. CrossRef Medline

Schallert T, Tillerson J (1999) Intervention strategies for degeneration of dopamine neurons in parkinsonism: optimizing behavioral assessment of outcome. In: Central nervous system diseases (Emerich D, Dean R, Sanberg P, eds), pp 131-151. Totowa, NJ: Humana.

Starr MS, Summerhayes M (1983a) Role of the ventromedial nucleus of the thalamus in motor behavior. I. Effects of focal injections of drugs. Neuroscience 10:1157-1169. CrossRef Medline

Starr MS, Summerhayes M (1983b) Role of the ventromedial nucleus of the thalamus in motor behavior. II. Effects of lesions. Neuroscience 10: 1171-1183. CrossRef Medline

Stein E, Bar-Gad I (2013) beta oscillations in the cortico-basal ganglia loop during parkinsonism. Exp Neurol 245:52-59. CrossRef Medline

Tachibana Y, Iwamuro H, Kita H, Takada M, Nambu A (2011) Subthalamo-pallidal interactions underlying parkinsonian neuronal oscillations in the primate basal ganglia. Eur J Neurosci 34:1470-1484. CrossRef Medline

Weinberger M, Mahant N, Hutchison WD, Lozano AM, Moro E, Hodaie M, Lang AE, Dostrovsky JO (2006) Beta oscillatory activity in the subthalamic nucleus and its relation to dopaminergic response in Parkinson's disease. J Neurophysiol 96:3248-3256. CrossRef Medline

Wilson CJ (2013) Neuroscience forefront review active decorrelation in the basal ganglia. Neuroscience 250:467-482. CrossRef Medline 